\title{
Proposta de um método para atingir a manufatura responsiva na indústria de calçados: implantação e avaliação por meio de uma pesquisa-ação
}

\author{
Proposal of a method to achieve responsive manufacturing \\ in the footwear industry: implementation and assessment \\ through research-action
}

\author{
Flavio Cesar Faria Fernandes ${ }^{1}$ \\ Eduardo Gracia' ${ }^{1}$ \\ Fábio Molina da Silva ${ }^{1}$ \\ Moacir Godinho Filho'
}

\begin{abstract}
Resumo: Várias estratégias (Manufatura em Massa Atual, Manufatura Enxuta, Manufatura Responsiva, Customização em Massa, Manufatura Ágil,...) propõem-se a auxiliar as empresas na gestão da manufatura. O foco deste artigo é a Manufatura Responsiva (MR). O contexto em que se aplica a MR é a alta variedade de produtos feitos sob encomenda tendo como um fator crítico de sucesso o tempo de resposta (diferença entre a data em que o cliente recebe o atendimento de seu pedido e a data em que o cliente faz o pedido) que deve ser o menor possível, porém sem deteriorar os níveis de produtividade e qualidade. No Brasil, a MR é pouco conhecida e não utilizada de maneira formal. O objetivo deste estudo é propor e avaliar, por meio de uma pesquisa-ação, uma sistemática para atingir a MR em fábricas de calçados. Para a grande maioria dos fabricantes de calçados, a redução do tempo de resposta representa um importante trunfo competitivo. Dentre os resultados obtidos da implantação do método proposto na empresa Kidy, destacam-se: redução substancial do tempo de resposta, reduções de custos produtivos e de mão de obra, aumento nas quantidades de pedidos atendidos dentro dos prazos e diminuição dos índices de retrabalho.

Palavras-chave: Manufatura responsiva. Planejamento da produção. Controle da produção. Indústria de calçados. Produção sob encomenda. Arranjo físico.
\end{abstract}

\begin{abstract}
There are several strategies (Modern Mass Production, Lean Manufacturing, Responsive Manufacturing (RM), Mass Customization, Agile Manufacturing, etc) that can be used to aid manufacturing management in enterprises. This paper focuses on Responsive Manufacturing. RM is applied in environments of high variety of made-to-order product, in which response time (the elapsed time between the end of an inquiry and the beginning of a response) is a critical factor and should be minimum without diminishing quality and disrupting productivity. In Brazil, RM is not well known or frequently used. The objective of this study is to propose and evaluate, by means of an action-research, a method to achieve RM in the footwear industry. For the majority of the footwear manufacturers, the reduction in response time represents a key competitive advantage. Among the main results obtained with the implementation of the proposed method in the company studied (Kidy) are: substantial reduction of response time, reduction of production and labor costs, increase of service level, and reduction of rework rate.
\end{abstract}

Keywords: Responsive manufacturing. Production planning. Production control. Footwear industry. Make-to-order. Layout.

\section{Introdução}

As empresas estão sempre reestruturando pelo menos algum de seus processos para se manterem ou se tornarem competitivas no globalizado mercado mundial. No ramo de calçados a busca por competitividade é muito grande (FERNANDES; MURARI, 2000) por ser um setor em que a concorrência é (quase) perfeita (número muito

grande de empresas competindo), há uma diferença considerável entre oferta e procura, a competição externa é marcante, é altamente dependente de mão de obra e seus produtos acompanham a tendência da moda internacional, o que dificulta muito a organização interna do seu planejamento e controle da produção (PCP). Várias pesquisas (p. ex. SILVA;

\footnotetext{
${ }^{1}$ Departamento de Engenharia de Produção - DEP, Universidade Federal de São Carlos - UFSCar, Rod. Washington Luís, Km 235, CEP 13565-905, São Carlos, SP, Brasil, e-mail: dfcf@ufscar.br
} 
FERNANDES, 2008) vêm sendo feitas com o objetivo de contribuírem para a melhoria desse segmento, e este trabalho vem complementar essas pesquisas e ajudar fabricantes de calçados nacionais a serem mais competitivos. O objetivo deste estudo é propor e avaliar, por meio de uma pesquisa-ação, a sistemática GEST/ProdCal que faz parte da linha de pesquisa GEST do grupo de pesquisa PLACOP (PLAnejamento e COntrole da Produção). PLACOP é um grupo de pesquisa registrado no $\mathrm{CNPq}$ e liderado pelo primeiro autor deste artigo. A sistemática GEST/ProdCal foi proposta para auxiliar fabricantes de calçados atingirem a Manufatura Responsiva (MR).

$\mathrm{O}$ método de pesquisa utilizado neste artigo é a pesquisa-ação. Conforme Miguel (2010), os métodos de pesquisa mais aplicados à área de engenharia de produção são: survey, modelagem, simulação, teórico/ conceitual, estudos de caso e pesquisa-ação. Segundo Thiollent (2000), pesquisa-ação é um tipo de pesquisa social com base empírica, concebida e realizada em estreita associação com determinada ação ou com a resolução de um problema coletivo. $\mathrm{Na}$ pesquisa-ação, pesquisadores de um lado, participantes representativos da situação ou do problema no outro, estão envolvidos de modo cooperativo ou participativo. A pesquisa caminhou exatamente nesse sentido. Ao longo da aplicação foram surgindo oportunidades de melhoria, as quais se refletiram na proposta mostrada neste trabalho. Embora um projeto de pesquisa-ação não tenha forma totalmente pré-definida, Thiollent (1997) considera, no mínimo, quatro grandes fases: i) Fase exploratória, na qual os pesquisadores e alguns membros da organização começam a detectar os problemas, os atores, as capacidades de ação e os tipos de ação possíveis; ii) Fase de pesquisa aprofundada, na qual a situação é pesquisada por meio de diversos tipos de instrumentos de coleta de dados, que são discutidos e progressivamente interpretados pelos participantes; iii) Fase da ação, que consiste, com base nas investigações em curso, em difundir os resultados, em definir objetivos alcançáveis por meio de ações concretas e em apresentar propostas, cuja aplicação poderá ser negociada com os dirigentes da empresa; iv) Fase de avaliação, que tem por objetivos: observar, redirecionar o que realmente acontece e armazenar o conhecimento adquirido no decorrer do processo. No início da pesquisa, essas quatro fases são sequenciais, mas, na prática, existe entre as três últimas fases um tipo de vaivém ou mesmo de simultaneidade de pesquisa e de ação (THIOLLENT, 1997). Coughlan e Coghlan (2002) enfatizam que pesquisa-ação é pesquisa em ação e não uma pesquisa sobre a ação, envolve dois objetivos (resolver um problema e contribuir para a ciência), é interativa, cooperativa e holística, lida diretamente com mudança, etc. Esses autores trazem muitas informações úteis de como desenvolver uma pesquisa-ação na área de gestão da produção.

O objeto de estudo é a Kidy, um grande fabricante de calçados infantis localizado na cidade de Birigui-SP. Seus trabalhadores tiveram forte influência na pesquisa, caracterizando-a como pesquisa-ação; a propósito, vale destacar que o segundo autor deste artigo era gerente de produção da unidade da Kidy, na qual a sistemática proposta neste artigo foi implantada pela primeira vez.

O processo cíclico (veja TURRIONI; MELLO, 2010) de cinco passos desta pesquisa-ação compreendeu:

i) planejamento da pesquisa que compreende: a proposta da sistemática (seções 3 e 4) a ser implantada, o aval do presidente da empresa, e a definição do responsável pela coordenação da implantação (o gerente da produção já citado neste artigo);

ii) coleta de dados (os dados necessários foram coletados e os principais estão explicitados na seção 5);

iii) análise de dados (apresentação na seção 5);

iv) tomada de ação: a ação mais demorada foi a mudança de layout, e uma das ações mais críticas para o sucesso da pesquisa-ação foi a conscientização do programador da produção sobre as vantagens da implantação da sistemática proposta;

v) avaliação da ação. Com a implantação da sistemática foram obtidos alguns resultados altamente positivos: redução substancial do tempo de resposta, reduções de custos produtivos e de mão de obra, aumento nas quantidades de pedidos atendidos dentro dos prazos e diminuição dos índices de retrabalho.

Os fabricantes de calçados geralmente privilegiam um dos seguintes conjuntos de objetivos de desempenho: i) produzir em grandes volumes obtendo baixo custo (isso nos remete à Manufatura em Massa Atual); ii) a qualidade de seus produtos porém sem se descuidar da eliminação de desperdícios (Manufatura Enxuta); iii) outras enfatizam a flexibilidade e o atendimento com pontualidade dos clientes, sem se esquecer de qualidade e custo (Manufatura Responsiva). O presente artigo se destina a auxiliar na gestão da manufatura das empresas pertencentes principalmente a esse terceiro grupo.

Como toda pesquisa científica, este artigo é um desdobramento (ou continuação) de trabalhos anteriores, entre eles, vários trabalhos do grupo PLACOP/GEST/ProdCal: diagnóstico de problemas na indústria calçadista que merecem ser estudados em detalhes (LEITE; FERNANDES, 2003); programação 
da produção de calçados sob encomenda em ambiente propício para se aplicar a lógica do sistema de coordenação de ordens PBC (sobre o PBC veja BURBIDGE (1996)) e obter responsividade (SILVA; FERNANDES, 2008); conceituação de manufatura responsiva (STALK, 1988; STALK; HOUT, 1990; FERNANDES; MACCARTHY, 1999) e sistemáticas para se obter a responsividade (BLACK, 1991; SURI, 1998, 2010). A sistemática aqui apresentada e aplicada é uma compilação, adaptação e desdobramento de procedimentos que aparecem em vários trabalhos, sendo os principais: Burbidge (1989), Black (1991), Silva e Fernandes (2008) e Fernandes, Godinho Filho e Bonney (2009).

Cachon e Swinney (2011) apontam que na indústria de moda rápida (que é o caso da indústria de calçados) há necessidade de combinar as capacidades da Manufatura Responsiva (também chamada de TBC (Competição Baseada no Tempo) e de Manufatura de Resposta Rápida (QRM)) e as capacidades de projeto de produtos "quentes" que capturam a última tendência dos consumidores. Essa combinação deve levar em conta a obtenção de lead times (de projeto (LPr), de produção (LP)) mínimos com vistas a atender a uma demanda incerta. Note que quando o projeto é feito após a confirmação do pedido do cliente então (FERNANDES; GODINHO FILHO, 2010): $($ tempo de resposta $)=(\operatorname{LPr})+($ lead time de suprimento $)+(\mathrm{LP})+($ lead time de distribuição) .

Uma estratégia de aplicação mais abrangente que a MR, mas a ela relacionada, é a estratégia QR (Quick Response). A prática da QR consiste em:

[...] o fornecedor recebe os dados de como estão as vendas e os níveis de estoque de seus itens nos pontos de vendas dos clientes; com isso, o fornecedor pode melhorar sua programação da produção ou pode definir de forma mais adequada os parâmetros das regras de controle que ele usa para regular o fluxo de materiais. (FERNANDES; GODINHO FILHO, 2010, p. 179)

Segundo Wanke (2008), a QR tem impacto não só na produção, mas também na distribuição ao movimentar rapidamente os produtos acabados dos fornecedores para os clientes por meio do cross-docking; se eliminam estoques intermediários entre eles e o que se tem é um estoque em trânsito. A evolução dos programas de QR pode ser observada em Hunter e Valentino (1995) e em Drake e Marley (2009). As aplicações de QR são muitas e entre elas: Perry e Sohal (2001) e Forza e Vinelli (1997).

Os benefícios da QR pela redução do descompasso entre a demanda e a oferta têm sido apontados em inúmeros trabalhos, por exemplo: Fisher e Raman (1996) e Fisher, Rajaram e Raman (2001). Duas das principais estratégias que auxiliam a atingir os objetivos da QR são: i) Manufatura Responsiva; ii) postergação. Sobre postergação veja o artigo de Hoek (2001).

A estrutura deste artigo prossegue assim: na seção 2, tratamos da contextualização de Manufatura Responsiva e das sistemáticas de Black (1991) e de Suri $(1998,2010)$ para obter responsividade; nas seções 3 e 4, apresentamos nossa proposta para atingir a responsividade na indústria de calçados; na seção 5, apresentamos a implantação da proposta em uma grande fabricante de calçados, bem como mostramos os resultados obtidos desta implantação; finalmente, na seção 6, apresentamos algumas conclusões.

\section{Manufatura Responsiva}

\subsection{Contextualização}

A Competição Baseada no Tempo (TBC) foi primeiro proposta por Stalk e Hout (1990) para os casos em que o tempo é o principal fator competitivo. É afirmado que executivos de empresas agressivas estão alterando seus padrões de desempenho, passando de custos e qualidade competitiva para custos, qualidade e responsividade. Existem companhias que estão alcançando notáveis resultados ao colocar suas organizações no enfoque da responsividade.

Blackburn (1991) cita que a manufatura baseada no tempo deve implementar uma série de métodos destinados a reduzir o tempo de resposta aos clientes. Handfield (1995) diz que tempo de produção reduzido traz benefícios indiretos para a empresa, ou seja, menos estoques e maior rapidez no atendimento ao cliente. Handfield e Bechtel (2002) afirmam que, para existir a responsividade, deve haver confiança e comprometimento muito grande entre cliente e fornecedores. Intensa troca de informações se faz necessária para que não ocorra problema no suprimento.

Outras referências de interesse:

- Liang e Guo (2009) constroem um modelo markoviano para avaliar os processos de desenvolvimento do produto em termos da missão tempo.

- Stump e Badurdeen (2009) apresentam uma estrutura que mostra como diversas estratégias (MR, Teoria das Restrições, Sistemas de Manufatura Reconfiguráveis ou Flexíveis,...) podem ser integradas com a Manufatura Enxuta em ambientes de Customização em Massa.

- No contexto da MR, Upton (1995) pesquisa quais são os fatores que mais impactam a flexibilidade relacionada com a habilidade do processo mudar rapidamente de um produto para outro.

- Fiorito, May e Straughn (1995) definem e discutem a relação da $\mathrm{QR}$ com várias estratégias e entre elas a Manufatura de Ciclo Curto. 
Vale a pena ressaltar que a Manufatura Responsiva (MR) não é para todos. Por exemplo, suponha que a estratégia adequada de resposta à demanda seja MTS (make-to-stock) e um fabricante pensa em primeiro implantar uma estratégia QR (Quick Response) em ambiente MTS e depois, numa segunda etapa, pensaria em adotar um atendimento à demanda MTO (make-to-order) suportada pelos princípios da MR. Porém, a QR poderá não vingar e enterrar a segunda etapa. Por quê? Para compreender isso, leia o artigo de Krishnan, Kapuscinski e Butz (2010), no qual se demonstra que baixos estoques a jusante (motivado, por exemplo, pela diminuição de lead time) acabam gerando um desincentivo ao esforço de vendas no varejo, e o varejista acaba privilegiando produtos de um concorrente que não adote $\mathrm{a} \mathrm{QR}$.

Rohr e Corrêa (1998) propõem a seguinte sistemática, cujos procedimentos devem ser incansavelmente explorados para que as empresas possam competir em tempo: 1) eliminação das atividades que não adicionam valor; 2) melhor coordenação entre as atividades (integração); 3) redução do tempo das atividades que adicionam valor. A seguir duas sistemáticas mais detalhadas.

\subsection{Sistemáticas para obter a responsividade}

Nesta seção, são apresentadas as sistemáticas de Black (1991) e Suri $(1998,2010)$ para se obter responsividade (pequenos tempos de resposta num ambiente com alta distinção (variedade de modelos semelhantes) e/ou com média ou alta diversificação (variedade de produtos muito diferentes).

\subsubsection{Sistemática de Black (1991)}

A sistemática de Black (1991) é denominada por IMPS e está intimamente relacionada à manufatura de células interligadas. A IMPS visa gerar, de forma flexível, produtos de qualidade superior a um menor custo possível com entregas no prazo. Conceitualmente a IMPS situa-se entre a Manufatura Enxuta e a Manufatura Responsiva. A IMPS alicerça-se em 10 procedimentos (esses procedimentos poderiam ser colocados na forma de princípios e então denominaríamos de estratégia de Black (1991) ao invés de sistemática de Black (1991)):

P1) Forme as células (de manufatura e de montagem).

P2) Implemente um sistema de redução de setup.

P3) Integre o controle de qualidade.

P4) Integre a manutenção preventiva para obter confiabilidade de máquinas

P5) Nivele e balanceie a montagem final.
P6) Integre o controle da produção: interconecte as células por meio do kanban.

P7) Integre o controle de estoques: reduza os estoques em processo para que os problemas sejam expostos.

P8) Expanda o sistema derivado da IMPS de modo que ele abranja os fornecedores

P9) Nas células em que for conveniente, coloque robôs e/ou aumente o nível de automação.

P10) Computadorize de forma a conectar o sistema de células interligadas ao sistema de produção. Esse procedimento deve ser o último a ser implementado, ou seja, deve ser o último passo para se obter um sistema integrado de manufatura. Sua implementação se faz usando tecnologias tais como: CAD (computer-aide d design), CAM (computer-aided manufacturing) e CNC (computer numerical control) ou DNC (direct numerical control), protocolos de automação MAP/TOP. Ao computadorizar um sistema integrado, o sistema IMPS (sistema resultante da aplicação dos procedimentos da sistemática IMPS) se torna um sistema CIMPS (Computerized Integrated Manufacturing Production System).

\subsubsection{Sistemática de Suri $(1998,2010)$}

A sistemática de Suri $(1998,2010)$ é denominada QRM (Quick Response Manufacturing). Essa sistemática apoia-se em dez procedimentos fundamentais:

P1) Encontre um modo novo para executar os trabalhos, com foco na redução do lead time.

P2) Planeje a capacidade dos recursos críticos em 80 ou $70 \%$.

Muitos gerentes acreditam que, para realizar os trabalhos mais rápidos, é necessário manter as máquinas e pessoas ocupadas o tempo todo. Entretanto, essa política de $100 \%$ de utilização gera longos lead times, crescimento das filas, trabalhos esperando por recursos.

P3) Adote a redução do lead time como a principal medida de desempenho.

P4) Insista na medição e na recompensa da redução de lead times.

P5) Utilize o MRP para planejar e coordenar materiais e reestruturar a organização da manufatura em células mais simples, orientadas a produto.

O MRP é poderosa ferramenta para planejamento e coordenação de materiais, mas não é ferramenta voltada à redução do lead time. Para que isso seja realizado, é necessário que o MRP seja reestruturado 
para ser utilizado como ferramenta de planejamento em nível mais alto e para fornecer autorizações; mas não é adequado para gerir materiais e informações dentro das células.

Suri recomenda que seja utilizado um sistema de coordenação de ordens, denominado POLCA, que combina os melhores aspectos dos sistemas de coordenação de ordens dentre os que puxam e os que empurram a produção. Informações sobre o sistema de coordenação de ordens POLCA podem ser obtidas em Suri (1998, 2010), Fernandes e Carmo-Silva (2006) e Riezebos (2010).

P6) Motive seus fornecedores para que eles também implementem a QRM.

P7) Eduque seus clientes sobre as vantagens do QRM e negocie um programa de entregas de lotes menores a preços razoáveis.

P8) Elimine as barreiras funcionais.

As células terão um importante papel na implantação deste procedimento.

P9) Justifique porque a empresa deve adotar a QRM.

O cliente precisa pagar mais pela rapidez de entrega, o que representa bom resultado, mas isso não deveria ser a razão principal do QRM. Buscando novos meios de comprimir o tempo teríamos o resultado que simboliza menos desperdício.

P10)Combata, por meio de treinamento, os preconceitos que atrapalham a implantação da sistemática QRM.

\section{Sistemática GEST/ProdCal para obter responsividade na indústria de calçados}

A sistemática GEST/ProdCal para atingir a responsividade na indústria calçadista se compõe dos seguintes procedimentos:

P1) Alterar características do produto que possibilitem eliminar operações produtivas, sem que a qualidade e a estética do calçado sejam alteradas.

Análise de Valor (AV; para itens em produção) e Engenharia de Valor (EV; para itens ainda em fase de projeto) foram escolhidas como ferramentas para implementar este procedimento.

Análise de Valor na indústria de calçados consiste basicamente em identificar as funções do calçado, avaliá-las e finalmente propor forma alternativa de desempenhá-las de maneira mais conveniente do que a conhecida, reduzindo assim os custos de produção e de mão de obra.

P2) Simplificar ao máximo o fluxo de materiais.

Acredita-se que a simplificação do fluxo de materiais no chão de fábrica é extremamente favorável à redução do tempo de resposta do sistema de produção, redução que enseja maior pontualidade nas entregas. E o modo mais eficaz de conseguir esta simplificação é a utilização do layout em grupo (celular), o qual divide todos os componentes em famílias e todas as máquinas em grupos, de sorte que todos os elementos de uma família são processados num único grupo de máquinas. Esse grupo recebe o nome de célula.

Para formar o layout celular, Burbidge (1989) indica como melhor método o Production Flow Analisys (PFA). O PFA foi desenvolvido por Burbidge na década de 1960 e, consiste em cinco subtécnicas sucessivas, a saber:

- CFA (Company Flow Analysis): Simplificação dos fluxos entre fábricas ou divisões. Para encontrar a melhor divisão de cada fábrica dentro de departamentos baseados na organização por produto.

- FFA (Factory Flow Analysis): Simplificação dos fluxos de materiais entre os departamentos da fábrica.

- GA (Group Analysis): Divisão de departamentos em Grupo.

- LA (Line Analysis): Estudo dos materiais entre os centros de trabalho por meio da análise de linha.

- TA (Tool Analysis): Análise do Ferramental ao encontrar itens de uma família que utilizam as mesmas ferramentas, com o objetivo de planejar o sequenciamento das operações e conjuntos de partes aptas à automação (BURBIDGE, 1989).

P3) Subdividir o processo em unidades produtivas de acordo com os tipos de layouts.

Na manufatura discreta que não atua pelo paradigma Manufatura em Massa Atual, tem-se três tipos de unidades produtivas:

- Unidade produtiva do tipo 1 - Células com padrão de fluxo flowshop (mesmo roteiro para todos os itens produzidos na célula)- layout celular;

- Unidade produtiva do tipo 2 - Células com padrão de fluxo jobshop (fluxos apresentando contrafluxo) - layout celular;

- Unidade produtiva do tipo 3 - Pequenos jobshop - layout funcional.

P4) Classificar as unidades produtivas.

Classificar as unidades produtivas utilizando o sistema de MacCarthy e Fernandes (2000), no qual a principal variável é o nível de repetição do sistema de produção. Se houver coerência no projeto das unidades produtivas, devemos ter que:

- unidades produtivas do tipo 1 correspondam aos sistemas repetitivos;

- unidades produtivas do tipo 2 correspondam aos sistemas semirrepetitivos;

- unidades produtivas do tipo 3 correspondam aos sistemas não repetitivos. 
Por essa classificação, verifica-se que a MR contém os três sistemas, com maior predominância do sistema semirrepetitivo, dada sua significativa variedade de produtos.

O sistema de classificação de MacCarthy e Fernandes (2000) considera as seguintes variáveis envolvidas: 1) tamanho da empresa; 2) tempo de resposta; 3 ) nível de automação; 4) nível de repetição; 5) estrutura do produto; 6) nível de customização; 7) número de produtos; 8) tipos de layout; 9) tipos de estoque, 10) tipos de fluxo; 11) tipos de montagem e 12) tipos de organização do trabalho.

P5) Escolher os Sistemas de Coordenação de Ordens (SCO) de produção e de compra mais adequados para cada unidade produtiva.

Sugere-se usar como critérios para tal escolha os critérios explicitados em MacCarthy e Fernandes (2000). A sistemática de MacCarthy e Fernandes (2000) sugere, por exemplo, que as unidades produtivas semirrepetitivas podem ser controladas convenientemente pelo sistema de coordenação de ordens PBC. Burbidge (1996) é o trabalho mais completo sobre o PBC; Benders e Riezebos (2002) mostram que o PBC não é um sistema ultrapassado e sim é um clássico; outro importante artigo é Zelenovic e Tesic (1987).

P6) Elaborar o Programa Mestre de Produção (MPS) de forma compatível com o sistema de coordenação de ordens adotado.

Como ferramentas para implantar este procedimento, usaremos: tempos cronometrados, tempos pré-determinados e a heurística de Silva e Fernandes (2008).

P7) Escolher um sistema apropriado para sequenciar as ordens de produção em cada setor produtivo (corte, pesponto e montagem). Devido à grande quantidade de tipos de matéria-prima contida em cada par de calçado, é muito importante ter critério para o sequenciamento da produção. A próxima seção apresenta a proposta deste artigo para sequenciar a produção. Ela faz parte da sistemática GEST/ProdCal.

P8) Considerar sempre os efeitos da velocidade na qualidade dos produtos. Este procedimento está apresentado, na forma de princípio, em Fernandes, Godinho Filho e Bonney (2009).

\section{Um método para sequenciamento da produção na indústria de calçados}

O sequenciamento da produção aqui proposto leva em conta as seguintes condições:

- o sistema de coordenação de ordens adotado é o PBC;
- a elaboração do MPS leva em conta a condição acima, os prazos de entrega, o balanceamento da capacidade e quebra de programação em diferentes estágios para cada ciclo. Considerando períodos de no máximo 1 dia, os estoques em processos são pequenos em relação ao volume de produção mensal.

Assim, pode-se pensar em sequenciar a produção em cada estágio produtivo, levando-se em conta as peculiaridades da indústria de calçados (setups irrelevantes, alta dependência de mão de obra, tempos de processamento curtos);

- os principais estágios de produção que devem ser controlados são: a) corte; b) pesponto; c) montagem;

- a lógica do PBC quando aplicada à indústria de calçados pode ser convenientemente representada pela Figura 1.

Para entender a Figura 1, focalizemos o período 6. Em tal período estamos realizando: o estágio $\mathrm{E}$ (expedição precedida ou não pelo acabamento) do ciclo 1; o estágio M (montagem sucedida ou não pelo acabamento) do ciclo 2 ; o estágio $\mathrm{P}$ (pesponto) do ciclo 3; o estágio C (corte) do ciclo 4; o estágio S (obtenção (suprimento) e separação dos materiais) do ciclo 5. Além disso, no período 6, estão sendo recebidos e acumulados os pedidos que serão programados para o ciclo 6 ou para um ciclo posterior ao ciclo 6 .

As ordens de produção devem estar de acordo com o setor transformador (corte, pesponto e montagem), isto é, um sequenciamento para cada setor. No corte, as ordens devem ser sequenciadas por material para reduzir o tempo de setup. Por exemplo, na Tabela 1 , como há 6 tipos de materiais, haverá 5 ou 6 setups. Admitindo que cada material possui 3 modelos, se o sequenciamento for por modelo então o número de setups pode chegar a 18 .

\subsection{Proposta}

\subsubsection{Primeiro passo}

Criar uma matriz que identifique o tempo de setup entre a troca de materiais. A Tabela 1 mostra uma matriz com 6 materiais.

Pela Tabela 1, para mudar, por exemplo, do corte do material 1 para o material 2 , incorre-se num tempo de setup de 140 segundos.

\subsubsection{Segundo passo}

Definir a sequência das ordens de produção após a definição dos tempos de setup. Deve-se iniciar a produção pelos modelos cujos materiais são mais 
difíceis de manipular; pois, quando os operários iniciam o turno, estão descansados e com mais energia, aptos a render mais nas tarefas difíceis.

Daí para a frente, é só aplicar a conhecida heurística SST (Shortest Setup Time), ou seja, depois de esgotado o material difícil, inicia-se a produção do segundo mais difícil de menor setup. Este processo dever ser realizado até que todos os materiais estejam sequenciados.

Suponha-se que na Tabela 1 o material mais difícil de ser cortado seja o material 4. Começa-se pelo $4 \mathrm{e}$ vai-se ou para o 2 ou para o 6 , ambos com setup igual a 15 segundos. Admitindo-se que o material 2 seja mais difícil de ser cortado que o 6 , então corta-se o 2. Admitindo-se que o material 3 seja mais difícil de cortar que o 6, a sequência será: 4-2-3-1-5-6.

No pesponto, existem duas situações: a primeira surge quando a indústria não tem padronização de cor de linha de costura; a segunda situação ocorre nas indústrias com padronização de até 4 cores de linhas.

No primeiro caso, devem ser sequenciadas as ordens de produção por modelo, criando-se matriz que identifique os tempos de setup entre as trocas de modelos. Inicia-se a produção pelo modelo mais difícil e, em seguida, o segundo modelo mais difícil de menor setup. Daí para a frente utiliza-se a heurística SST até que todos os modelos sejam sequenciados, analogamente ao sequenciamento do corte.

No segundo caso, o sequenciamento das ordens deve ser efetuado pelas cores das linhas de costura, desprezando-se o tempo de setup, ou seja, devem-se juntar todos os modelos de mesma cor de linha, o que formará quatro grupos (padrão de 4 cores de linha); verifica-se então qual dos grupos tem o maior volume de modelos mais difíceis de pespontar (costura) e inicia-se a produção por este grupo e pelo modelo mais difícil dentro dele; em seguida, o segundo modelo mais difícil (não havendo necessidade de troca de linha); ao término do grupo ocorre então a troca de linha e inicia-se a produção do segundo grupo com a maior quantidade de modelos difíceis e assim por diante. Durante todo o dia de trabalho acontecerão apenas 4 trocas de linhas.

Para exemplificar o sequenciamento do segundo caso (pesponto), a Figura 2 mostra esquema deste caso para três cores de linhas e cinco modelos, em que a sequência de modelos mais difíceis é a seguinte: 1) Modelo X, 2) Modelo Y, 3) Modelo Z, 4) Modelo H, e 5) Modelo M. O grupo 1 de cor de linha Azul tem prioridade de entrada sobre os outros grupos por ter os modelos mais difíceis (Xe Y).

No setor de montagem, a proposta é produzir conforme a liberação do pesponto e separar os pedidos na expedição. Isso reduzirá o estoque entre os dois setores e o de expedição terá flexibilidade para priorizar clientes conforme a necessidade das entregas.

Tabela 1. Tabela de setups por materiais (Dados em segundos).

\begin{tabular}{ccccccc}
\cline { 1 - 4 } Para & \multirow{2}{*}{$\mathbf{1}$} & $\mathbf{2}$ & $\mathbf{3}$ & $\mathbf{3}$ & $\mathbf{5}$ & $\mathbf{6}$ \\
\cline { 1 - 5 } 1 & - & 140 & 15 & 140 & 15 & 140 \\
2 & 140 & - & 140 & 15 & 140 & 15 \\
3 & 15 & 140 & - & 140 & 25 & 140 \\
4 & 140 & 15 & 140 & - & 140 & 15 \\
5 & 15 & 14 & 1 & 14 & - & 60 \\
6 & 140 & 15 & 140 & 15 & 140 & - \\
\hline
\end{tabular}

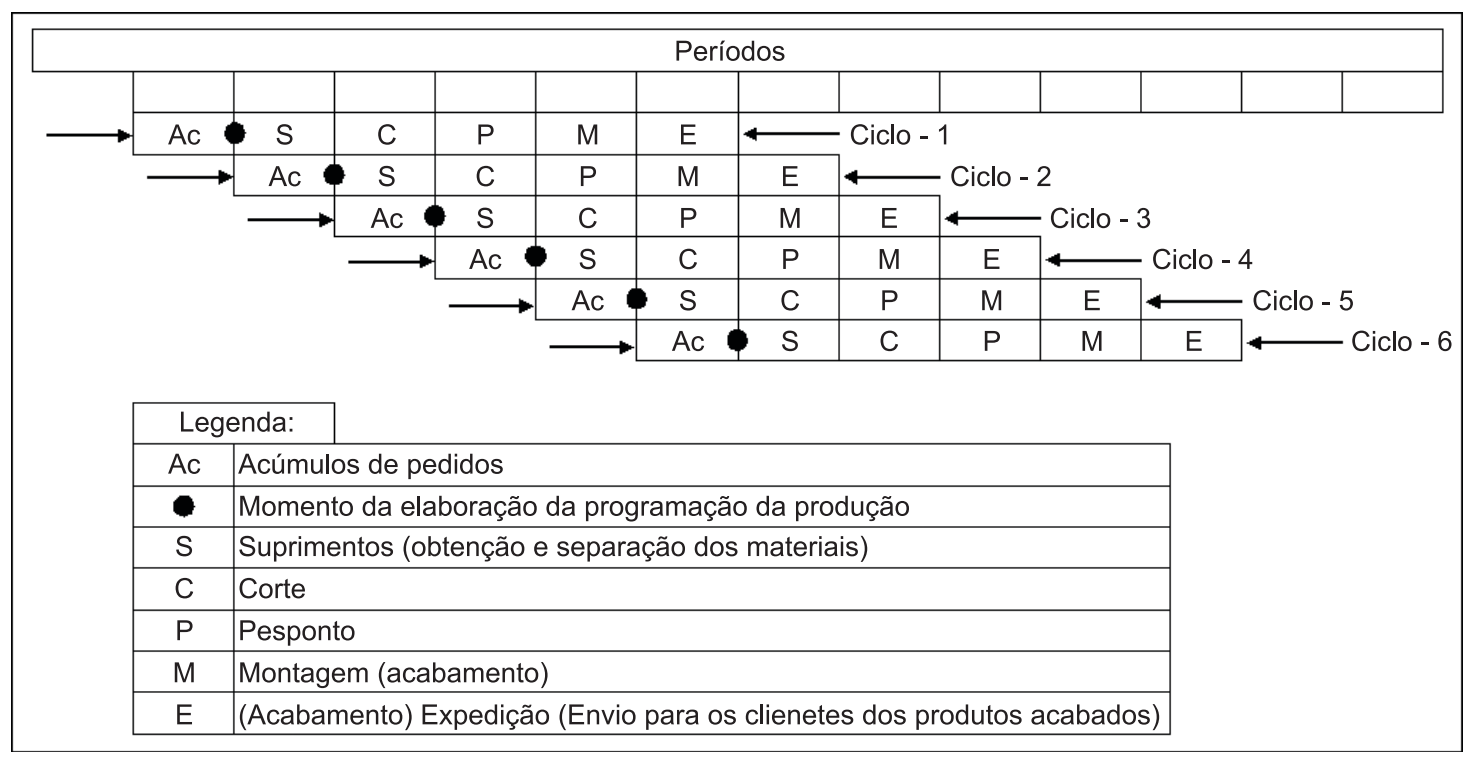

Figura 1. Estrutura lógica do funcionamento do PBC na indústria de calçados. 


\section{Manufatura Responsiva na indústria de calçados: uma pesquisa-ação}

\subsection{Objeto de estudo}

A Kidy Birigui Calçados Ind. Com. Ltda. emprega hoje 1600 funcionários diretos. Produz 22.000 pares/ dia de calçados infantis, tudo sob encomenda. Esse volume de calçados é produzido em 8 unidades. Cada unidade responde por um segmento especial de calçado, ou seja, uma unidade produz tênis; outra, botas; e assim por diante. Realizou-se a pesquisa-ação na unidade produtiva "Fábrica 6".

A Fábrica 6 é especializada em sandálias, com capacidade produtiva de 1800 pares por dia. No início da pesquisa, havia 105 pessoas trabalhando no processo produtivo, em uma área de $440 \mathrm{~m}^{2}$. Detalhes sobre layout e movimentações de materiais estão nas seções seguintes.

Com responsabilidade de $8 \%$ da produção total da Kidy, a Fábrica 6 passava por dificuldades no processo produtivo, com mão de obra ociosa e atraso no atendimento aos pedidos. Esse o grande motivo da parceria Kidy-PLACOP para implantação da MR naquela unidade produtiva.

\subsection{Aplicação da proposta}

A proposta foi implantada em etapas, a saber:

Etapa 1) Transmissão inteligível a todos os envolvidos na implantação o que é a Manufatura Responsiva e quais são os seus benefícios

A pesquisa veio ao encontro de uma necessidade e deu início à caminhada em busca da Manufatura Responsiva. Segundo o Diretor Industrial da Kidy Calçados, Ricardo Gracia, "a alta exigência dos clientes, de rapidez no atendimento, de pontualidade e de diversidade de produtos, foi a razão que nos levou a procurar alternativas de produção". Todos os envolvidos no processo tornaram-se conscientes da responsabilidade de cada um para ser alcançada a almejada responsividade.

Etapa 2) Implantação dos procedimentos e ferramentas vistos nas seções 3 e 4 .

\section{E2.1) Implantação do procedimento $P 1$ da seção 3}

Análise de Valor (AV) e Engenharia de Valor (EV) foram as ferramentas escolhidas para implantar o primeiro procedimento. No objeto de estudo, novos modelos entram em produção a cada três meses. Substituem os modelos menos aceitos no mercado. Foi utilizada EV para analisar e reduzir operações desnecessárias, desde a concepção dos novos modelos até sua entrada em produção. Quanto a modelos que permaneceram em produção, a AV foi aplicada, por exemplo: sugeriu-se eliminar uma costura em certa peça; recomendou-se nova tecnologia para pregar um velcro. Essas e dezenas de outras propostas facilitaram o processo produtivo da sandália, sem mudar em nada sua qualidade e sua estética. Considerável ganho também ocorreu na padronização de apenas 3 cores de linhas (preto, marrom e branco). Isso reduziu setup no processo e itens no almoxarifado. Todo o processo de AV contribuiu eficazmente para o próximo procedimento, pois ocorreu redução de postos de trabalho, facilitou o fluxo de produção e fortaleceu a união dos grupos de trabalho (células). Como um dos exemplos de êxito na aplicação da AV tem-se a Sandália Surfista modelo 6905 (Figura 3). A Tabela 2 resume o processo da análise da AV para o modelo 6905.

Mudanças: foram eliminadas duas costuras no modelo apresentado; subtraiu-se um processo operacional; e economizou-se matéria-prima (linha). Isso não resultou em prejuízo nem para a estética nem para a qualidade do produto.

\section{E2.2) Implantação do procedimento $P 2$ da seção 3}

Eis o conteúdo do segundo procedimento: simplificar ao máximo o fluxo de materiais, levando em conta o impacto: a) no controle/programação da produção; b) no balanceamento da capacidade de produção.

$\mathrm{Na}$ aplicação do PFA, como o objeto de estudo não se enquadra no CFA, a análise começou pelo FFA (Factory flow analysis), que estuda o fluxo entre fábricas e departamentos.

$\mathrm{Na}$ análise do FFA, pode-se destacar, na Kidy, a divisão em fábricas: da Fábrica 1 à Fábrica 8 (veja Figura 4). Cada fábrica é responsável por uma família de produtos. No entanto, o almoxarifado é central e a expedição compete a cada fábrica.

O segundo estágio da análise foi o GA (Group analysis). A principal ferramenta do GA é a resolução por matriz. No caso da Kidy, foram agrupados os equipamentos e as sequências operacionais da

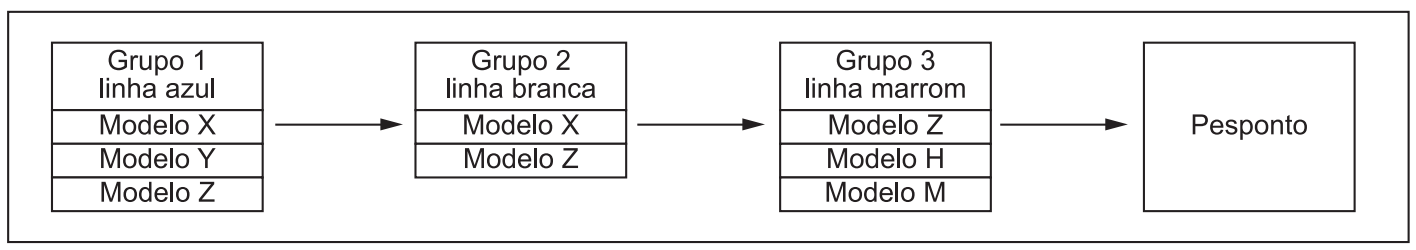

Figura 2. Exemplo de sequenciamento do pesponto. 
Tabela 2. Aplicação de AV ao modelo 6905.

\begin{tabular}{|c|c|c|c|c|}
\hline Componente & Função & $\mathbf{F} / \mathbf{E} / \mathbf{T}$ & $\mathbf{B} / \mathbf{S} / \mathbf{N}$ & Observações \\
\hline \multirow{4}{*}{ Sola } & Proteger pé & $\mathrm{F}$ & $\mathrm{B}$ & \\
\hline & Ser ante-derrapante & $\mathrm{F}$ & $\mathrm{B}$ & \\
\hline & Macia/Leve & $\mathrm{E}$ & $\mathrm{S}$ & \\
\hline & Durável & $\mathrm{F}$ & $\mathrm{S}$ & \\
\hline \multirow{2}{*}{ Palmilha } & Dar conforto & $\mathrm{E}$ & $\mathrm{S}$ & \\
\hline & Unir componentes a sola & $\mathrm{F}$ & $\mathrm{B}$ & \\
\hline \multirow{3}{*}{ Gáspea } & Segurar Proteger o pé & $\mathrm{F}$ & $\mathrm{B}$ & \\
\hline & Bonita & $\mathrm{E}$ & $\mathrm{S}$ & \\
\hline & Confortável & $\mathrm{E}$ & $\mathrm{S}$ & \\
\hline Forro da Gáspea & Conforto & $\mathrm{E}$ & $\mathrm{S}$ & \\
\hline Costura Forro/Gáspea & Unir forro/gáspea & $\mathrm{F}$ & $\mathrm{B}$ & \\
\hline \multirow{2}{*}{ Tira da Gáspea } & Ajuste de Tamanho & $\mathrm{F}$ & $\mathrm{B}$ & \\
\hline & Bonita & $\mathrm{E}$ & $\mathrm{S}$ & \\
\hline Velcro da Tira & Prender tira do cano & $\mathrm{F}$ & $\mathrm{B}$ & \\
\hline Costura do velcro/tira & Unir velcro/tira & $\mathrm{F}$ & $\mathrm{B}$ & \\
\hline Emborrachado tira da gáspea & Mostrar Marca & $\mathrm{E}$ & $\mathrm{S}$ & \\
\hline $\begin{array}{l}\text { Costura do emborrachado/tira } \\
\text { cano }\end{array}$ & Unir emb./cano & $\mathrm{F}$ & $\mathrm{N}$ & $\begin{array}{l}\text { Usar costura } \\
\text { velcro }\end{array}$ \\
\hline \multirow{3}{*}{ Passador Plástico } & Passar a tira & $\mathrm{F}$ & $\mathrm{B}$ & \\
\hline & Resistente & $\mathrm{F}$ & $\mathrm{B}$ & \\
\hline & Bonito & $\mathrm{E}$ & $\mathrm{S}$ & \\
\hline Costura do passador/cano & Unir passador no cano & $\mathrm{F}$ & $\mathrm{B}$ & \\
\hline \multirow{3}{*}{ Cano } & $\begin{array}{l}\text { Segurar Proteger o } \\
\text { Calcanhar }\end{array}$ & $\mathrm{F}$ & B & \\
\hline & Bonito & $\mathrm{E}$ & $\mathrm{S}$ & \\
\hline & Confortável & $\mathrm{E}$ & $\mathrm{S}$ & \\
\hline Forro Cano & Conforto & $\mathrm{E}$ & $\mathrm{S}$ & \\
\hline Costura Forro/Cano & Unir forro/cano & $\mathrm{F}$ & $\mathrm{B}$ & \\
\hline \multirow{2}{*}{ Tira do Cano } & Ajuste de Tamanho & $\mathrm{F}$ & $\mathrm{B}$ & \\
\hline & Bonita & $\mathrm{E}$ & $\mathrm{S}$ & \\
\hline Velcro da Tira & Prender tira do cano & $\mathrm{F}$ & $\mathrm{B}$ & \\
\hline Costura do velcro/tira & Unir velcro/tira & $\mathrm{F}$ & $\mathrm{B}$ & \\
\hline Emborrachado tira do cano & Mostrar Marca & $\mathrm{E}$ & $\mathrm{S}$ & \\
\hline $\begin{array}{l}\text { Costura do emborrachado/tira } \\
\text { do cano }\end{array}$ & Unir emb./cano & $\mathrm{F}$ & $\mathrm{N}$ & $\begin{array}{l}\text { Usar costura } \\
\text { velcro }\end{array}$ \\
\hline \multirow{3}{*}{ Passador Plástico } & Passar a tira & $\mathrm{F}$ & $\mathrm{B}$ & \\
\hline & Resistente & $\mathrm{F}$ & $\mathrm{B}$ & \\
\hline & Bonito & $\mathrm{E}$ & $\mathrm{S}$ & \\
\hline Costura do passador/cano & Unir Passador no cano & $\mathrm{F}$ & $\mathrm{B}$ & \\
\hline
\end{tabular}

Legenda F- funcional; E - estético; T - troca; B - básico; S - secundário; $\mathrm{N}$ - não necessário.

sandália, o que facilitou sobremodo a definição dos grupos de trabalho. Estabeleceram-se 8 grupos, acrescidos da linha de montagem e do setor de expedição. Na Tabela 3, está a relação dos grupos e do equipamento correspondente. $\mathrm{O}$ equipamento e a mão de obra de cada grupo foram definidos em função do balanceamento na época de implantação do Sexto Procedimento.
A terceira análise foi a LA (Line Analysis), que consiste no exame do fluxo de materiais entre os grupos ou estações de trabalho. A técnica utilizada na LA é igual a do FFA: lança-se mão de diagrama de rede para se entender e se melhorar o fluxo.

Esta etapa do estudo redundou em mudanças e melhorias significativas para a empresa, em termos de ganho de produtividade e mão de obra. É nesta análise 
que se deve levar em conta o impacto no controle/ programação da produção e o balanceamento da capacidade. A Figura 5 mostra o diagrama efetuado entre os 10 grupos de trabalho, relacionados na Tabela 3, definindo assim o novo layout do objeto de estudo.

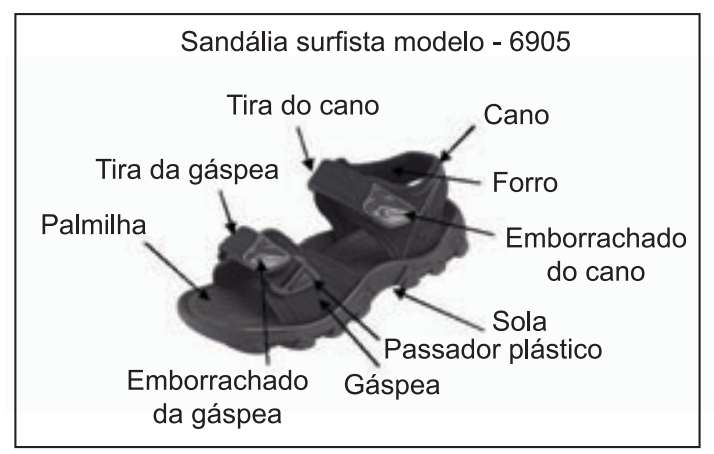

Figura 3. Sandália Surfista modelo 6905.
Para melhor compreensão dos ganhos nesta análise e do motivo real pelo qual se deve levar em conta o impacto no controle da produção, as Figuras 6 e 7 mostram o layout velho (LV) e o layout novo (LN). Este segue o modelo esquemático apresentado na Figura 5.

A primeira grande mudança ocorreu no espaço físico. É possível notar a diferença de escala do LV para o LN: no LV eram utilizados $440 \mathrm{~m}^{2}$ num barracão de 10 por 44 m, com 105 operários; já no LN utilizam-se $270 \mathrm{~m}^{2}$ (10 por $\left.27 \mathrm{~m}\right)$ e 81 operários. Vários motivos determinaram a redução de espaço, a saber, a Análise de Valor (VA), retirando operações desnecessárias, como foi visto na implantação do procedimento $\mathrm{P} 1$; a Análise de Grupo (GA), demonstrada nesta seção; e a definição dos tempos padrões, que será apresentada no tópico relativo à implantação do Sexto Procedimento.

Tabela 3. Relação dos grupos de trabalho da Fábrica 6.

\begin{tabular}{ccc}
\hline Grupo & Descrição & Equipamento \\
\hline 1 & Corte cabedal/componente & Balancin Alfa Click \\
2 & Aux. corte & Mesa \\
3 & Colar peças diversas & Mesa \\
4 & Colar e pespontar enfeites & Mesa/maq. pesponto coluna 1 agulha \\
5 & Pesponto e acabamento & Mesa/maq. pesponto coluna 1 agulha \\
6 & Pregar ponta e passador & Maq. pesponto coluna 1 agulha \\
7 & Destacar linha & Mesa \\
8 & Revisar & Mesa \\
9 & Montagem & Esteira \\
10 & Expedição & - \\
\hline
\end{tabular}

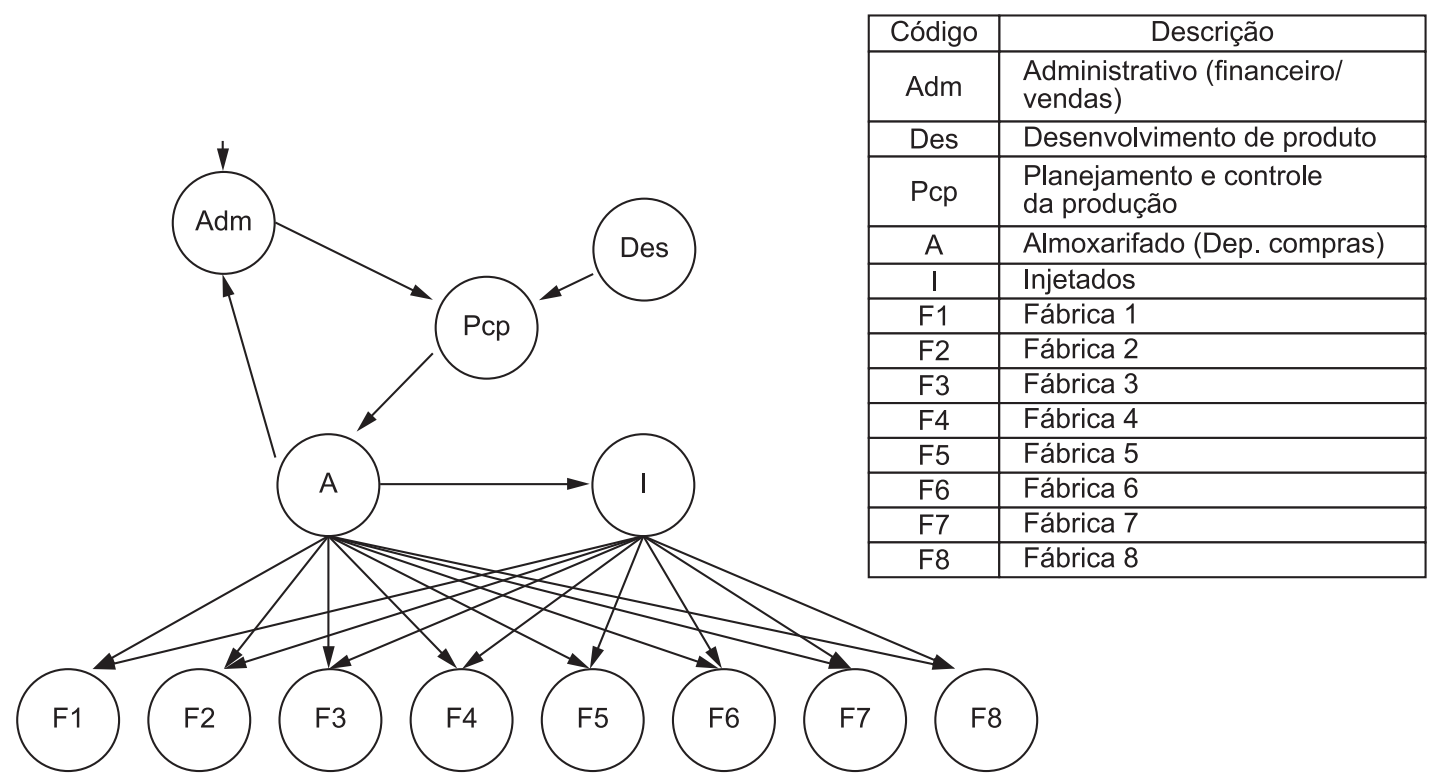

Figura 4. Divisão de departamentos Kidy. 


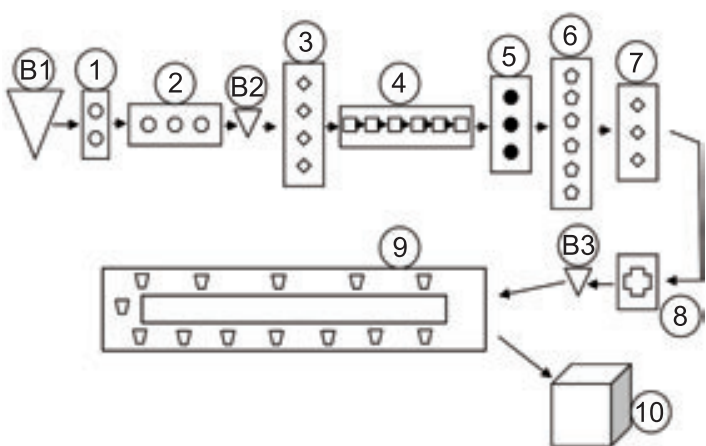

(1) Seção de corte (Máquinas em paralelo)

(2) Separação corte (Flow Shop)

(3) Colar peças para pesponto (Mesas em paralelo)

(4) Colar e pespontar enfeites (Flow Shop)

(5) Grupos de pesponto acabamento composto de máquinas e mesas paralelo

(6) Pregar ponta (Máquinas em paralelo)

(7) Recorte (Mesas em paralelo)

(8) Revisão qualidade

(9) Montagem

(10) Expedição

(B1) Buffer material do almoxarifado

(B2) Buffer entre corte e pesponto

(B3) Buffer para montagem

Figura 5. Layout esquemático do objeto de estudo.

O fluxo de materiais do LV aparenta mais simplicidade que o do LN, mas o novo layout proporciona uma flexibilidade maior. Para exemplificar a melhoria, foram separados os layouts em 3 grandes grupos: a) Corte (C), no qual são cortadas todas as peças superiores do calçado, com emprego de navalhas e máquina de grande porte (Balancim); b) Pesponto (P), no qual se faz a união destas peças por meio de costuras, com a utilização de mesas e máquinas de pesponto de uma agulha; c) Montagem (M), que finaliza o calçado, montando-o e colocando nele o solado.

Ainda com relação às figuras, os desenhos que contêm as siglas BAL representam máquinas de corte chamadas Balancim, a sigla $1 \mathrm{AG}$ representa máquina de costura (pesponto) de uma agulha, as demais máquinas podem ser identificadas no próprio desenho.

Comparando o primeiro grande grupo-Corte, houve diminuição de uma máquina, devido à redução do número de peças pela Análise de Valor. Essa diminuição foi comprovada pelo tempo-padrão. As Figuras 8 e 9 mostram como ficaram as alterações nesse setor.

O maior ganho fez-se sentir no Pesponto, pois a GA e AV ajudaram a deixar mais flexível esse setor. No $\mathrm{LV}$, o fluxo era mais simples, porém existia ociosidade

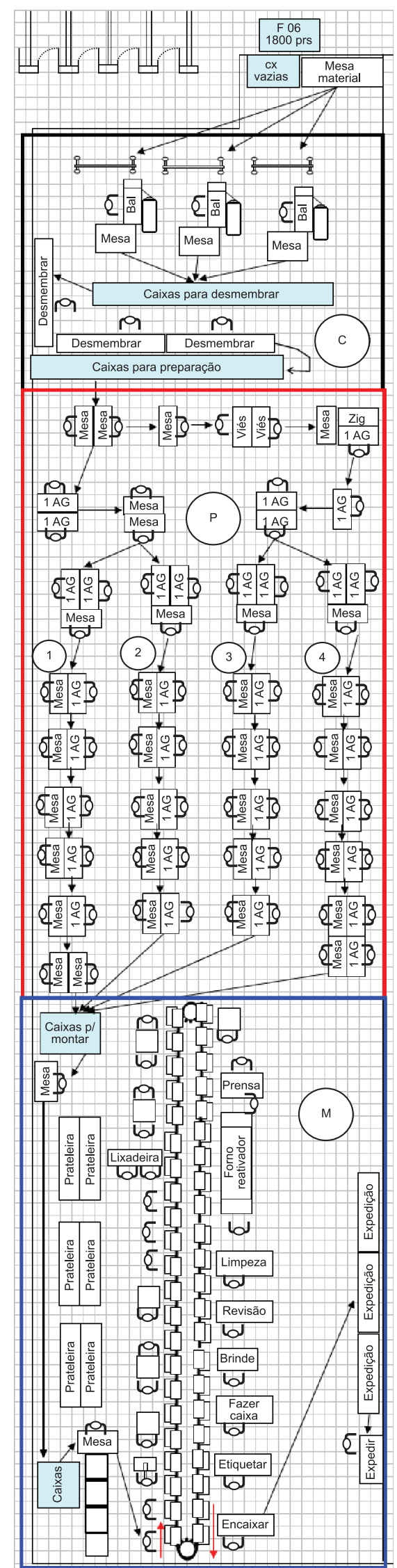

Figura 6. Layout Velho. 


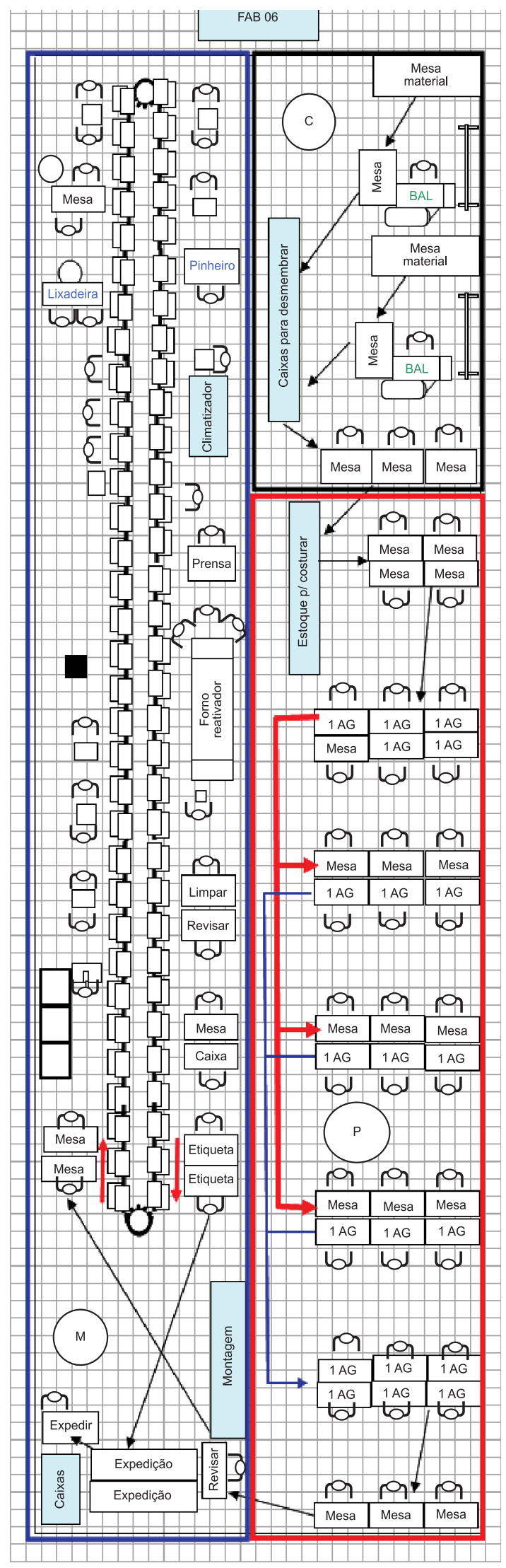

Figura 7. Layout Novo. de mão de obra. A demarcação na Figura 10, com os números 1-4 nas quatro linhas de pespontos, mostra que cada linha fabricava um único modelo, o que dificultava muito o balanceamento e a programação da produção. Havia momentos em que, devido à carteira de pedidos (produção sob encomenda), era impossível manter as 4 linhas em operação. No Layout Novo (LN), veja Figura 11, foram criados grupos flexíveis de trabalho, para fabricação de qualquer modelo, diminuindo assim a ociosidade de mão de obra. A redução do quadro de operários, em virtude do novo layout e da AV, foi surpreendente (de 69 para 37). Com isso, o programa da produção passou a atender aos clientes na data correta e não mais se preocupou com balancear a produção, o que, na $L V$, representava um desafio.

$\mathrm{O}$ grupo de montagem manteve os mesmos equipamentos. O LV e o LN da montagem estão nas Figuras 12 e 13, respectivamente. No processo de colagem, a qualidade melhorou. Aumentou-se o tamanho da esteira: aumentou-se o número de operários, de 29 para 36 , tudo para melhorar o processo de colagem e reduzir índices de retrabalho. Com mais passadores de cola, o trabalho pôde tornar-se mais lento ("a pressa é inimiga da perfeição"; princípio ligado ao oitavo procedimento). E com o aumento da esteira, houve tempo maior para a secagem da cola (obs.: a velocidade da esteira foi mantida no $\mathrm{LN}$ em relação à do $\mathrm{LV}$ )

$\mathrm{Na}$ Figura 13, aparece um cruzamento de fluxo de materiais. A solução para eliminar o cruzamento é muito simples. Deve-se rodar a esteira no sentido inverso. Infelizmente não foi possível fazê-lo, pelas condições do prédio. Para inverter a esteira, seria necessário inverter também a posição das máquinas e das mesas ao seu redor. Existia um pilar que impedia a localização do forno reativador. Então, decidiu-se não inverter a esteira e manter o cruzamento de materiais, uma vez que este cruzamento é insignificante em face do ganho que o LN proporcionou.

As grandes mudanças ocorridas com o número de operários estão diretamente relacionadas com os tempos-padrões estipulados pelos tempos cronometrados.

A quarta e última análise do PFA é a TA (Tooling Analysis), que estuda as famílias de ferramentas. Eventualmente elas podem ser unidas e, reduzir setup. Na indústria de calçados, em específico no corte, no pesponto e na montagem da Fábrica 6, as ferramentas (agulhas, guias entre outras) são fixas nas máquinas. O tempo exigido para trocá-las é desprezível (só são trocadas quando se quebram). Não há, pois, necessidade de focar a TA (Tool Analysis).

\section{E2.3) Implantação do procedimento $P 3$ da seção 3}

Este procedimento consiste em subdividir o processo em unidades produtivas de acordo com os tipos de layouts. 


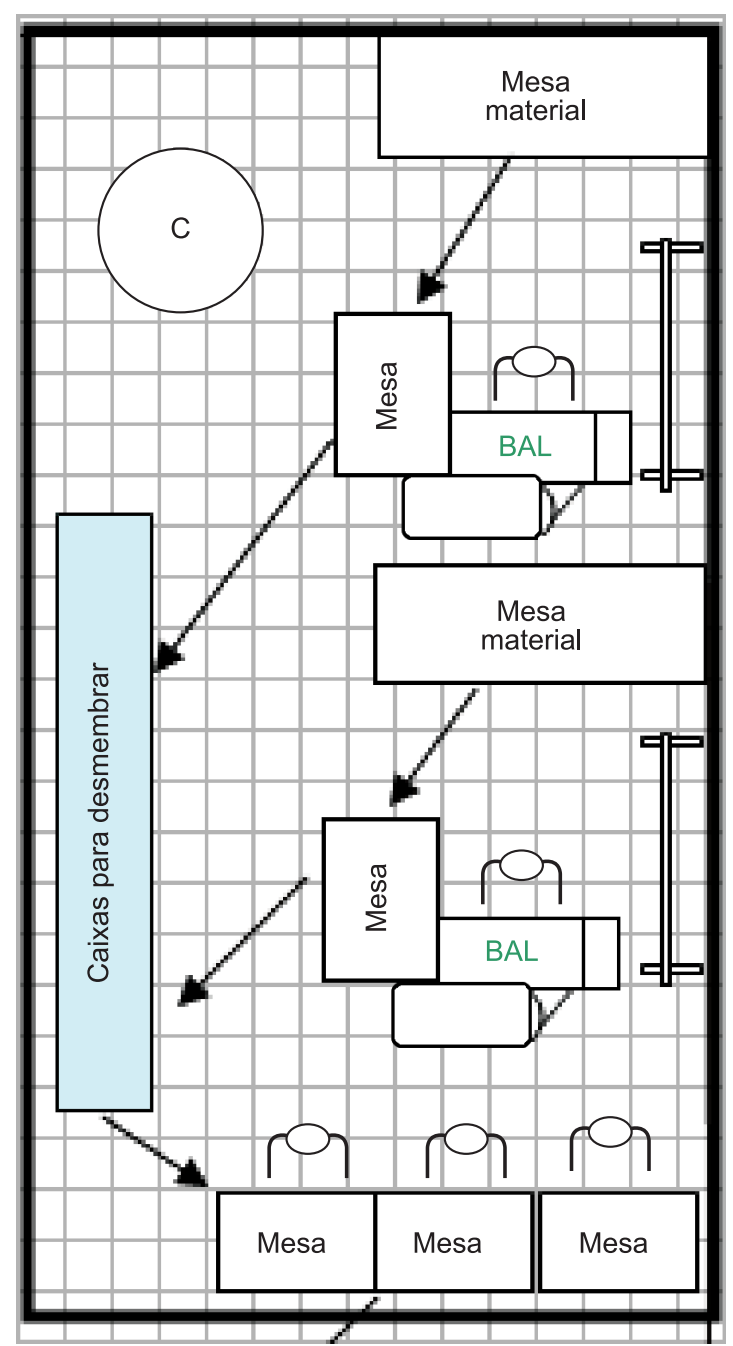

Figura 8. Layout Velho do Corte.

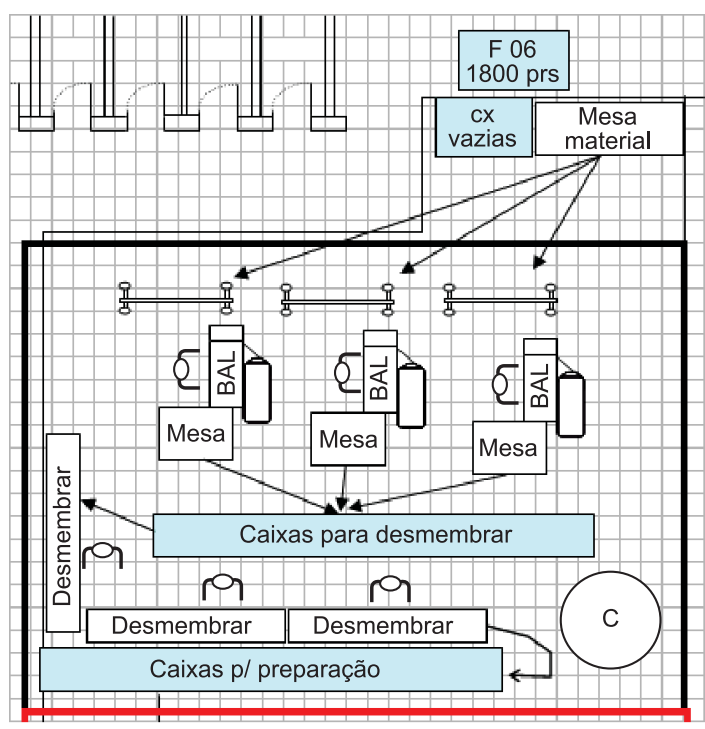

Figura 9. Layout Novo do Corte.

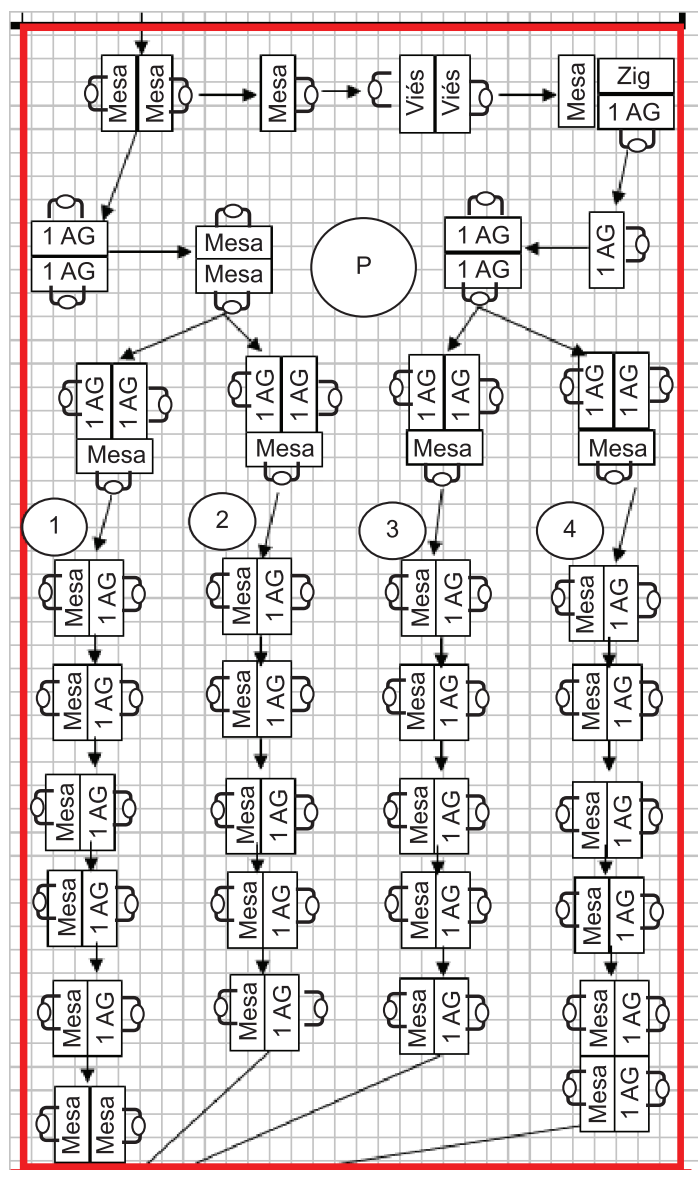

Figura 10. Layout Velho (LV) do pesponto.

Neste ponto aparece uma questão: a Fábrica 6 é um todo único ou compreende três unidades produtivas (corte, pesponto e montagem)?

No $5^{\circ}$ Princípio, será escolhido como SCO (Sistema de Coordenação de Ordens) o PBC. O PBC coordenará a produção do corte, do pesponto e da montagem. Consideramos assim, a Fábrica 6 como única unidade produtiva, composta por (Figura 6) 3 estágios de produção e 9 etapas (o estágio 1 é formado pelas etapas 1 e 2; o estágio 2 pelas etapas 3-8; e o estágio 3 pela etapa 9).

O layout desta unidade produtiva (Figura 6) é um layout com padrão de fluxo flowshop, sendo que nas etapas 1, 3, 5, 6 e 7 existem estações de trabalho em paralelo.

\section{E2.4) Implantação do procedimento $P 4$ da seção 3}

Classificar as Unidades Produtivas. Na seção anterior, o objeto de estudo se enquadrou como Unidade Produtiva do tipo 1, Isso significa que, observada a sequência da metodologia, há pré-indicação de que a unidade se vincule a um sistema repetitivo.

Caracterização mais detalhada, indicada por MacCarthy e Fernandes (2000), consiste em calcular a 


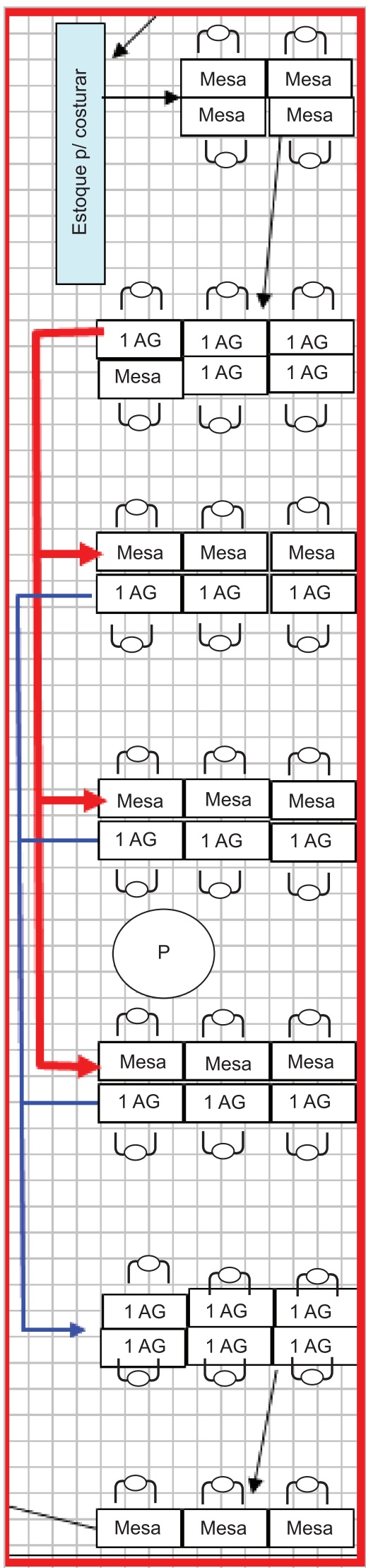

Figura 11. Layout Novo do pesponto. porcentagem de itens diferentes que sejam repetitivos. Se tivermos pelo menos $75 \%$ de itens repetitivos, o sistema é considerado repetitivo. Para o item ser repetitivo, deve utilizar pelo menos $5 \%$ da capacidade produtiva no horizonte de programação.

Uma primeira pergunta é: qual o número de itens considerados diferentes em termos de programação da produção na Fábrica 6? A diversificação na fábrica é de 8 modelos, cada qual com nove (9) números (a numeração vai do 28 ao 36), totalizando 72 itens. No estudo de tempo, para fins de programação da produção, consideram-se 8 itens ( 8 modelos), e não 72 itens; e cada um dos modelos ultrapassa os $5 \%$ de utilização da capacidade. A Fábrica 6 configura-se, portanto, como um sistema repetitivo.

Em relação ao sistema repetitivo, MacCarthy e Fernandes (2000) afirmam que: 1) Tamanho da empresa não influencia na classificação; 2) Tempo de resposta deve ser igual a PL (lead time de produção) +DL (lead time de distribuição); 3) Nível de Automação Normal (N) ou Flexível (F); 4) Nível de customização Mushroom ou Padronizado; 5) Tipo de layout em Grupo; 6) Tipo de buffer 1, 2 e 3; 7) Tipos de montagem A5, A6 ou A7. A Kidy se enquadrou em todas as características propostas, portanto não foi apontada nenhuma disfunção e, então, passou-se diretamente para o próximo procedimento (P5).

\section{E2.5) Implantação do procedimento P5 da seção 3}

Este procedimento consiste em escolher os sistemas de Coodernação de Ordens de produção e de compra ( $\mathrm{SCO}$ ) mais adequados para cada unidade produtiva.

De acordo com MacCarthy e Fernandes (2000), para unidades produtivas do tipo 1 (caso do objeto de estudo), o SCO mais adequado é o Kanban ou PBC.

Depois da análise dos processos e documentos da Fábrica 6, verificou-se já estar sendo usado algo muito próximo ao PBC como sistema de Coordenação de Ordens. Por conseguinte, nenhuma grande mudança foi necessária.

Mas a empresa, apesar de se utilizar desse sistema (aliás, ideal para suas características), desconhecia a teoria que embasa o PBC.

Portanto, nesta etapa de implantação, bastou explicar a metodologia do $\mathrm{PBC}$, a fim de que os envolvidos unissem a teoria à prática.

Detalhe interessante é que a Fábrica 6 mantinha nomenclatura para seus processos, mas diferente do que se encontra na literatura. O ciclo, por exemplo, é referido como "relatório diário de produção". Devido a esse hábito, há muito arraigado na empresa, não foi possível mudar a nomenclatura. Continua-se a chamar o "ciclo 1" de "relatório 1"; o relatório do PBC, "programação".

A Tabela 4 mostra o programa PBC do mês de M7/ A1 (sétimo mês a partir do ano A1 (ano da implantação 


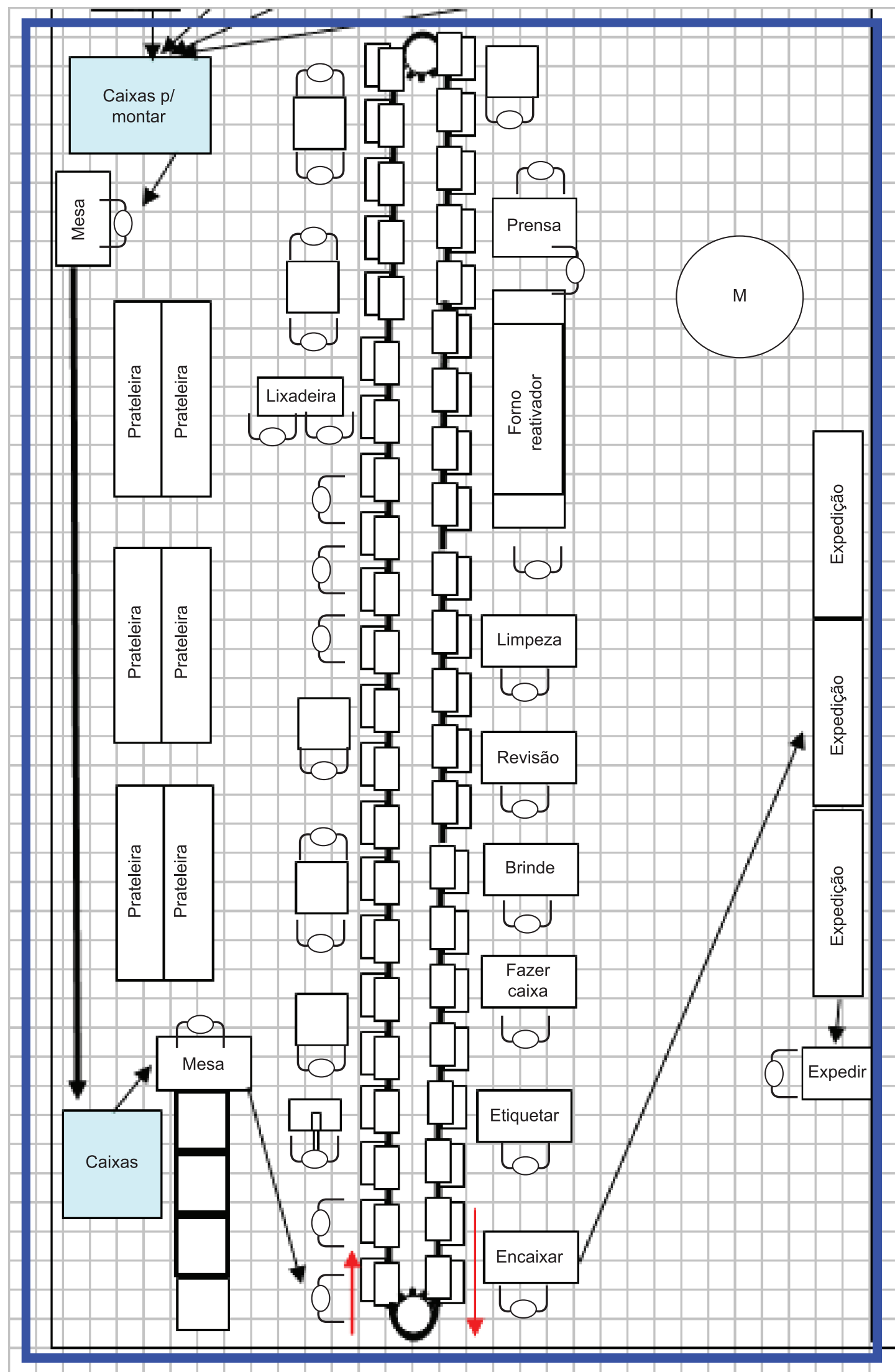

Figura 12. Layout Velho da Montagem. 


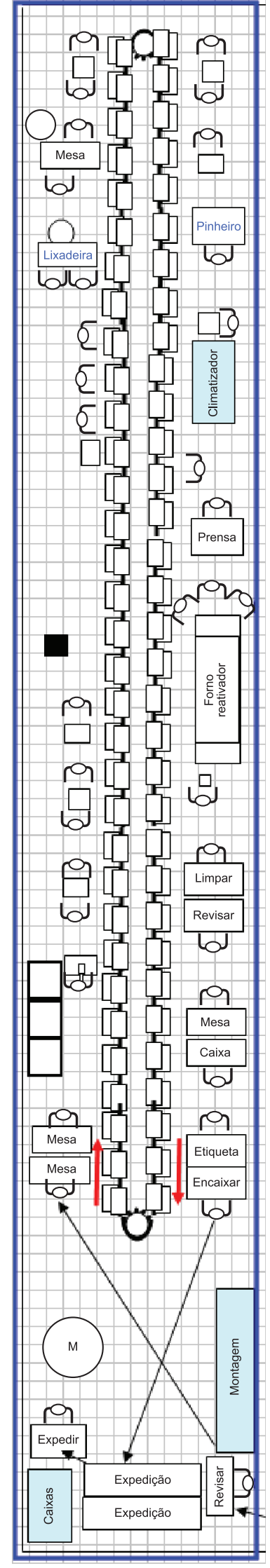

Figura 13. Layout Novo da Montagem. da sistemática GEST/ProdCal)). Por exemplo: no dia 2, o almoxarife está separando o material do ciclo 2; o corte está cortando o material do ciclo 1 ; o pesponto está costurando o material do ciclo 21 do mês anterior (ou seja, está atrasado; o problema de atrasos há de ser eliminado pelo principio 6 que tem como ferramenta o sistema Prodcal (Produção de calçados), que é uma implementação computacional desenvolvida em Delphi, para a heurística de Silva e Fernandes (2008); a montagem está montando o ciclo 20 (também atrasado); e, no mesmo dia 2, a expedição já vai despachando os pedidos do ciclo 20 .

\section{E2.6) Implantação do procedimento $P 6$ da seção 3}

Esse procedimento consiste na Elaboração do Programa Mestre de Produção (MPS=Master Production Schedule). Para implantá-lo, foi utilizado o Prodcal.

Estabeleceram-se, em primeiro lugar, os tempos-padrões das operações, Definiram-se as operações e os elementos, os quais foram cronometrados. Quanto a alguns elementos do pesponto, foram utilizados os tempos sintéticos. Com isso foi possível apurar os tempos-padrões das operações, alimentar o Prodcal e definir o total de mão de obra de equipamentos necessários para produção de 1800 pares por dia.

Para chegar aos 1800 pares diários, o departamento de vendas analisou os dados de vendas relativos aos últimos 24 meses. Obtendo média aritmética e admitindo potencial incremento dos negócios considerou realizável a venda de 1800 pares por dia. Contribuiu assim para aumento da participação dessa linha (Sandália Surfista) no mercado durante os anos A1 (ano da implantação) e A2 (ano seguinte à implantação).

Foram inseridos no Prodcal os tempos-padrões e também lançados os pedidos de vendas dos meses de outubro/A1 e novembro/A1. Em seguida, solicitou-se o cálculo do MPS para 2 períodos.

Várias melhorias aconteceram com a utilização do MPS. Detalhes importantes devem ser observados. O primeiro detalhe é a capacidade de utilização dos setores produtivos. Foi possível usar quase que $100 \%$ da capacidade produtiva dos setores (Tabela 4), aspecto que a Fábrica 6 não controlava. Suri (1998) contesta a utilização de $100 \%$ da capacidade de produção, afirmando que se uma operação for calculada em $80 \%$ na média, ela vai ser realizada sem stress. Obtém-se, assim, resultado melhor do que a operação a $100 \%$, na qual a pressão é maior e, em consequência, as falhas também. Retornando à indústria de calçados, a grande maioria dos processos é manual e foram determinados tempos-padrões para cada um deles. Esses tempos padrões são calculados a um ritmo de $80 \%$. Então os $100 \%$ da capacidade, citados 
acima, correspondem a quase $100 \%$, ou seja, 99,48 dos $80 \%$ estipulados nos tempos-padrões, o que resulta em utilização líquida de 79,58\% (Utilização líquida $\rightarrow 0,80 \times 0,9948=0,7958)$.

Uma fábrica tradicional que trabalhe com ritmo de $80 \%$ dos tempos-padrões e com capacidade utilizada em $80 \%$ terá uma capacidade líquida utilizada de apenas $64 \%$ (bem abaixo do percentual da proposta).

Outra mudança significativa residiu na quantidade de pares a serem produzidos diariamente. Todos na fábrica tinham meta de 1800 pares por dia. Como é possível ver no relatório do PBC (Tabela 4), a entrada e a saída são de 1800, mas, em fase da implantação do Prodcal e da verdadeira utilização do MPS, transformou-se a cultura interna. Os envolvidos compreenderam que a meta de produção depende do MPS, pois é ele que define a melhor utilização dos setores produtivos, de acordo com a quantidade de equipamento e mão de obra que os tempos-padrões estabeleceram. Com isso, a produção diária tem variação de 1600 a 2100 pares, dependendo da carteira de pedidos. Para que os operadores soubessem da meta do dia, a fábrica passou a efetuar simples reunião de, no máximo, 5 minutos, logo na primeira hora de trabalho. Foi denominada de matinal. A média diária, após a implantação consolidada do Prodcal, no período de 20 de novembro/A1 a 10 de dezembro/A1 foi de 1920 pares. Além do aumento de produtividade (aumento da produção com o mesmo número de trabalhadores), foi atendido número maior de pedidos/dia. Antes da implantação consolidada do Prodcal, a média era de 76 pedidos/dia. No período de 20 de novembro/A1 a 10 de dezembro/A1 a média passou a ser de 82 pedidos.

Tabela 4. Relatório PBC mês de M7/A1 para a Fábrica 6.

\begin{tabular}{|c|c|c|c|c|c|c|c|c|c|}
\hline \multicolumn{5}{|c|}{ Programação mês M7/ano A 1} & \multicolumn{2}{|c|}{ Fábrica 6} & & & \multirow[b]{2}{*}{ saída } \\
\hline & & entrada & almox & corte & pesp. & mont. & & & \\
\hline 1 & Dom & - & - & - & - & - & - & - & - \\
\hline 2 & Seg & 1800 & 2 & 1 & 21 & 20 & 20 & - & 1800 \\
\hline 3 & Terça & 1800 & 3 & 2 & 1 & 21 & 21 & - & 1800 \\
\hline 4 & Quarta & 1800 & 4 & 3 & 2 & 1 & 1 & - & 1800 \\
\hline 5 & Quinta & 1800 & 5 & 4 & 3 & 2 & 2 & - & 1800 \\
\hline 6 & Sexta & 1800 & 6 & 5 & 4 & 3 & 3 & - & 1800 \\
\hline 7 & Sábado & - & - & - & - & - & - & - & - \\
\hline 8 & Dom & - & - & - & - & - & - & - & - \\
\hline 9 & Seg & 1800 & 7 & 6 & 5 & 4 & 4 & - & 1800 \\
\hline 10 & Terça & 1800 & 8 & 7 & 6 & 5 & 5 & - & 1800 \\
\hline 11 & Quarta & 1800 & 9 & 8 & 7 & 6 & 6 & - & 1800 \\
\hline 12 & Quinta & 1800 & 10 & 9 & 8 & 7 & 7 & - & 1800 \\
\hline 13 & Sexta & 1800 & 11 & 10 & 9 & 8 & 8 & - & 1800 \\
\hline 14 & Sábado & - & - & - & - & - & - & - & - \\
\hline 15 & Dom & - & - & - & - & - & - & - & - \\
\hline 16 & Seg & 1800 & 12 & 11 & 10 & 9 & 9 & - & 1800 \\
\hline 17 & Terça & 1800 & 13 & 12 & 11 & 10 & 10 & - & 1800 \\
\hline 18 & Quarta & 1800 & 14 & 13 & 12 & 11 & 11 & - & 1800 \\
\hline 19 & Quinta & 1800 & 15 & 14 & 13 & 12 & 12 & - & 1800 \\
\hline 20 & Sexta & 1800 & 16 & 15 & 14 & 13 & 13 & - & 1800 \\
\hline 21 & Sábado & - & - & - & - & - & - & - & - \\
\hline 22 & Dom & - & - & - & - & - & - & - & - \\
\hline 23 & Seg & 1800 & 17 & 16 & 15 & 14 & 14 & - & 1800 \\
\hline 24 & Terça & 1800 & 18 & 17 & 16 & 15 & 15 & - & 1800 \\
\hline 25 & Quarta & 1800 & 19 & 18 & 17 & 16 & 16 & - & 1800 \\
\hline 26 & Quinta & 1800 & 20 & 19 & 18 & 17 & 17 & - & 1800 \\
\hline 27 & Sexta & 1800 & 1 & 20 & 19 & 18 & 18 & - & 1800 \\
\hline 28 & Sábado & - & - & - & - & - & - & - & - \\
\hline 29 & Dom & - & - & - & - & - & - & - & - \\
\hline 30 & Seg & 1800 & 2 & 1 & 20 & 19 & 19 & - & 1800 \\
\hline 31 & Terça & 1800 & 3 & 2 & 1 & 20 & 20 & - & 1800 \\
\hline
\end{tabular}


A única dificuldade surgiu no setor de montagem por ser constante a velocidade da esteira, para produção diária de 1800 pares. Para se produzir de acordo com MPS (oscilações de 1600 a 2100 pares), foi proposto aos trabalhadores da montagem um sistema de Banco de Horas, segundo o qual eles ficam em serviço além do horário, quando necessário, e saem mais cedo, quando o MPS é menor que 1800 pares por dia.

Outro detalhe importante é que, embora o Prodcal elabore todo o MPS automaticamente, não foi possível substituir pelo sistema o programador, pois uma verificação final no MPS é muito importante. Pode haver alguma restrição (como, por exemplo, financeira) que não tenha sido possível programar a tempo, e ele pode ser gerado e ocasionar problemas futuros, como estoques de produtos acabados.

Depois de ser conscientizado das vantagens de usar o ProdCal, o próprio programador sugeriu uma inovadora melhoria no sistema: a possibilidade de marcar pedidos que contenham restrições de última hora e gerar novo MPS para que outra utilização dos setores produtivos seja calculada. Hoje o sistema só permite exclusão do pedido.

\section{E2.7) Implantação do procedimento $P 7$ da seção 3}

A implantação do método de sequenciamento proposto na seção 4 foi muito simples. No pesponto após a padronização de 3 cores de linhas, a solução estabelecida foi juntar todos os modelos que utilizam a mesma cor de linha e sequenciá-los, do mais difícil para o mais fácil, e efetuar, se possível, apenas 3 trocas de linha no dia todo. Com isso não houve necessidade de confecção da matriz com os tempos de setup. Percebeu-se a satisfação das pespontadeiras com a redução da tarefa de trocar linha.

Já no corte, a dificuldade são os materiais: existem vários tipos e, para cada tipo, corresponde uma regulagem de máquina (setup). Nesse caso, elaborou-se a matriz de dependência de setups (Tabela 5) para poder aplicar a proposta da seção 4 deste artigo.

No setor da montagem, o sequenciamento é efetuado conforme a liberação do pesponto. A expedição separa os pedidos de acordo com sua prioridade.
E2.8) Implantação do procedimento P8 da seção 3

Este procedimento tem por finalidade garantir a qualidade dos produtos dentro da visão responsiva, isto é, conciliando velocidade e qualidade.

No objeto de estudo (Fábrica 6), deu-se grande importância a esse procedimento. Como pode ser visto na implantação do segundo procedimento, especificamente na linha de montagem, ocorreu aumento de mão de obra para garantir os índices aceitáveis de qualidade.

A velocidade da linha de montagem permaneceu constante, porém, com aumento dos operadores, ocorreu melhora significativa no índice de retrabalho, que passou de 3,5\% da produção diária (último mês de Janeiro antes da implantação da sistemática) para $1,9 \%$ (dados relativos última semana do terceiro mês da implantação da sistemática). Comprova-se assim a grande importância desse procedimento na indústria de calçados.

O objeto de estudo adota tolerância de 1,5\% para índice de retrabalho, o que ainda não está sendo alcançado pela montagem, porém, treinamentos estão sendo realizados para capacitar ainda mais a mão de obra. São considerados retrabalhos todos os processos refeitos, como colar novamente uma palmilha, tirar rebarbas da sola, etc.

A velocidade exerce muita influência nos processos produtivos de calçados, pois não adianta querer acelerar o processo sem respeitar os tempos de secagem requeridos pelas colas e pelos solventes. Deve-se procurar alternativa para a obtenção de ganhos de produtividade sem prejudicar a qualidade. Exemplo: máquinas que auxiliem no processo de secagem.

\subsubsection{Terceiro passo: selecionar medidas de desempenho para a MR}

Foram selecionadas seis medidas de desempenho para a MR, específicas para a indústria de calçados:

- Tempo de resposta total do sistema;

- Porcentagem das entregas no tempo devido;

- Tempo de resposta da empresa em relação ao tempo de resposta médio da indústria;

- Lead time de produção;

- Número de novos produtos lançados no mercado em dado período;

- Tempo de lançamento médio de novos produtos.

Tabela 5. Setup setor de corte (tempos em segundos).

\begin{tabular}{|c|c|c|c|c|c|}
\hline & Sintético & Lycra & Pluma & Forro & Velcro \\
\hline Sintético & - & 15 & 45 & 15 & 80 \\
\hline Lycra & 15 & - & 45 & 15 & 80 \\
\hline Pluma & 30 & 30 & - & 30 & 40 \\
\hline Forro & 15 & 15 & 45 & - & 80 \\
\hline Velcro & 60 & 60 & 30 & 60 & - \\
\hline
\end{tabular}




\subsubsection{Quarto passo: monitorar}

Com a implantação da sistemática, o tempo de resposta total do sistema passou de 25 a 30 dias para 20 dias. No caso da empresa, quando o vendedor visita o cliente, leva consigo a data possível de entrega, mas comunica ao cliente que a data pode variar em 3 dias para cima ou para baixo. Em outras palavras, o cliente efetua pedido para entrega no dia 10; assim, poderá receber entre os dias 7 e 13. A concorrência trabalha com tempo de resposta na faixa de 25 a 35 dias e com uma média 50\% maior que o tempo de resposta atualmente praticado na Kidy.

Como o sistema de produção permanece sob o controle do PBC, que tem ciclos de duração pré-estabelecidos, a Fábrica 6 possui lead time de produção de 4 dias. Se houver necessidade de reduzi-lo, poder-se-ia adotar períodos de 0,5 dia e, então, o lead time de produção passaria a ser de 2 dias (4 estágios (suprimento, corte, pesponto e montagem $) \times(0,5 \mathrm{dia}))$, porém haveria necessidade de contratar mais separadores de materiais, o que representaria um custo.

A porcentagem das entregas no tempo devido também está sendo monitorada. Hoje, em média, a Fábrica 6 atende a 1.300 pedidos por mês (o equivalente a aproximadamente 36.000 pares/ mês); o percentual de entregas na data correta situa-se em torno de $86 \%$ ou seja, aproximadamente 1.100 pedidos estão sendo atendidos na data prometida. Esse índice

Quadro 1. Resumo da relação entre ganhos, procedimentos e ferramentas utilizadas.

\begin{tabular}{|c|c|c|c|}
\hline Procedimentos & Ferramenta utilizada & Ganhos aplicação & Responsividade \\
\hline $\begin{array}{c}\text { Alterar características do } \\
\text { produto que possibilitem } \\
\text { eliminar operações produtivas, } \\
\text { sem que a qualidade e a } \\
\text { estética do produto sejam } \\
\text { alteradas. }\end{array}$ & Análise de valor. & $\begin{array}{c}\text { Padronização de } \\
\text { materiais, eliminaram-se } \\
\text { processos desnecessários } \\
\text { e facilitou-se a } \\
\text { fabricação. }\end{array}$ & $\begin{array}{l}\text { Redução no tempo } \\
\text { de operações. }\end{array}$ \\
\hline $\begin{array}{c}\text { Simplificar ao máximo o } \\
\text { fluxo de materiais levando em } \\
\text { conta o impacto no controle } \\
\text { da produção e em especial no } \\
\text { balanceamento da capacidade e } \\
\text { a programação da produção. } \\
\end{array}$ & $\begin{array}{c}\text { PFA (Production Flow } \\
\text { Analysis). }\end{array}$ & $\begin{array}{c}\text { Definiram-se layouts } \\
\text { mais flexíveis, melhor } \\
\text { utilização de espaço fixo. }\end{array}$ & $\begin{array}{l}\text { Flexibilizou o } \\
\text { processo. }\end{array}$ \\
\hline $\begin{array}{c}\text { Subdividir os processos em } \\
\text { unidades produtivas de acordo } \\
\text { com tipos de layouts. }\end{array}$ & $\begin{array}{l}\text { Layouts celular (com padrão de } \\
\text { fluxo flow shop ou job shop), } \\
\text { funcional e por produto. }\end{array}$ & Rapidez no fluxo. & Rapidez no fluxo. \\
\hline $\begin{array}{l}\text { Classificar as unidades } \\
\text { produtivas. }\end{array}$ & $\begin{array}{c}\text { Sistema de classificação } \\
\text { de sistemas de produção } \\
\text { MacCarthy e Fernandes (2000). } \\
\text { Espera-se predominância } \\
\text { dos sistemas de produção } \\
\text { semirrepetitivos. }\end{array}$ & $\begin{array}{c}\text { Ficou enquadrada como } \\
\text { sistema repetitivo. }\end{array}$ & Fluxo simplificado. \\
\hline $\begin{array}{c}\text { Escolher os sistemas de } \\
\text { Coordenação de Ordens de } \\
\text { Produção e Compra mais } \\
\text { adequados para cada unidade } \\
\text { produtiva. }\end{array}$ & $\begin{array}{l}\text { Escolha baseada na classificação } \\
\text { multidimensional de MacCarthy } \\
\text { e Fernandes (2000). }\end{array}$ & $\begin{array}{c}\text { Utilização de PBC } \\
\text { fixando realmente o lead } \\
\text { time de produção em } 4 \\
\text { dias. }\end{array}$ & $\begin{array}{c}\text { Fixou realmente } \\
\text { o lead time de } \\
\text { produção em } 4 \text { dias. }\end{array}$ \\
\hline $\begin{array}{c}\text { Elaboração do Programa } \\
\text { Mestre de Produção (MPS). }\end{array}$ & $\begin{array}{c}\text { Tempos cronometrados e } \\
\text { tempos pré-determinados e } \\
\text { heurística para elaborar o MPS } \\
\text { (Prodcal). }\end{array}$ & $\begin{array}{c}\text { Aumento na utilização } \\
\text { dos processos produtivos } \\
\text { e aumento na quantidade } \\
\text { de pedidos atendidos. } \\
\end{array}$ & $\begin{array}{l}\text { Aumento de pedidos } \\
\text { atendidos no prazo. }\end{array}$ \\
\hline $\begin{array}{l}\text { Escolher sistema apropriado } \\
\text { para sequenciar as ordens } \\
\text { de produção em cada setor } \\
\text { produtivo (corte, pesponto e } \\
\text { montagem). }\end{array}$ & Proposta da seção 4 deste artigo. & $\begin{array}{l}\text { Ganho de produção, } \\
\text { redução de setup e } \\
\text { satisfação dos operários. }\end{array}$ & $\begin{array}{l}\text { Eliminaram-se } \\
\text { Setups } \\
\text { desnecessários. }\end{array}$ \\
\hline $\begin{array}{c}\text { Considerar sempre os efeitos } \\
\text { da velocidade na qualidade dos } \\
\text { produtos. }\end{array}$ & $\begin{array}{c}\text { Gráficos que relacionam efeitos } \\
\text { da velocidade nas taxas de } \\
\text { refugo. }\end{array}$ & $\begin{array}{l}\text { Aumentou-se a linha de } \\
\text { montagem e diminuiu } \\
\text { o ritmo, para respeitar } \\
\text { os tempos de processo e } \\
\text { melhorar a qualidade. }\end{array}$ & $\begin{array}{l}\text { Melhoria na } \\
\text { qualidade. }\end{array}$ \\
\hline
\end{tabular}


é um dos pontos a serem melhorados no sistema. Futuras pesquisas poderão auxiliar na consecução de índice mais próximo de $100 \%$.

O número de novos produtos lançados no mercado em dado período e o tempo de lançamento médio desses novos produtos são prioridades no objeto de estudo. A empresa lança de três a quatro novos modelos a cada 3 meses.

Os dados acima são médias acompanhadas desde a implantação da proposta (fevereiro/A1) até julho/A2. A execução do sistema ainda está se aperfeiçoando. A própria curva de aprendizagem do uso do sistema trará melhorias.

\section{Conclusões}

Entre as diferenças e semelhanças entre as três sistemáticas voltadas à sustentação da Manufatura Responsiva destacam-se: i) o sistema de coordenação de ordens (SCO) empregado para sustentar a estratégia de Black é o Kanban, a de Suri é o POLCA e a sistemática aqui proposta (GEST/ ProdCal) adota uma abordagem contingencial (depende do tipo de unidade produtiva), sendo que, na pesquisa-ação na Kiddy utilizou-se o PBC; ii) em termos de estrutura de chão de fábrica, as duas primeiras exigem que o sistema seja composto por células e a GEST/ProdCal é mais flexível: na pesquisa-ação o primeiro processo possui máquinas em paralelo com a mesma função, o segundo são células em paralelo e o terceiro processo, uma linha de montagem cadenciada mecanicamente.

O Quadro 1 apresenta um resumo da aplicação dos procedimentos da sistemática GEST/ProdCal em termos da relação entre os ganhos, os procedimentos e as ferramentas utilizadas. Concluiu-se que os resultados foram altamente positivos, superando as expectativas da empresa.

A aplicação da sistemática GEST/ProdCal reduziu de 105 para 81 o número de operários na Fábrica 6, que tinha como gerente de produção, na época, o segundo autor deste artigo. Isso não quer dizer que 24 foram demitidos; foram realocados. Desde o início da implementação até os dias de hoje, a Kidy se tornou muito mais competitiva (é fato que isso não se deve exclusivamente à implantação da sistemática GEST/ ProdCal; por exemplo, a forma de desenvolver novos produtos e a taxação anti-dumping de calçados chineses tiveram um impacto maior) e cresceu de maneira vertiginosa (cresceu de cerca de 450 funcionários para mais de 1500 funcionários diretos).

$\mathrm{O}$ presente artigo cumpre os dois principais objetivos da pesquisa-ação: resolve um problema prático real e contribui com a ciência na medida em que propõe uma sistemática capaz de responder à questão de pesquisa: "como podemos diminuir o tempo de resposta de fabricantes de calçados que operam sob encomenda em ambiente em que a variedade de produtos é alta e novos produtos estão sempre sendo lançados"? Para pesquisas futuras tem-se a adaptação da sistemática GEST/ProdCal para ser aplicada em outros ramos ou segmentos industriais. Espera-se, por exemplo, que poucas adaptações serão necessárias para aplicá-la em certos segmentos do ramo de confecções; já a sua aplicação à indústria de bens de capital certamente envolverá adaptações muito significativas. Isso é esperado porque, quanto maior a similaridade entre os processos de fabricação do segmento a ser considerado e o segmento calçadista considerado neste artigo, menores serão as adaptações necessárias da sistemática GEST/ProdCal. Outra possibilidade de pesquisa futura é verificar a validade da seguinte hipótese: "Se a QR não for importante, a MR também não será e, se a QR for importante, há alta possibilidade de a MR ser importante". A propósito: Cachon e Swinney (2009) definem três tipos de consumidores e mostram que o valor da QR para um varejista é muito maior se existirem consumidores estratégicos do que se eles não existirem.

\section{Referências}

BENDERS, J.; RIEZEBOS, J. Period batch control: classic, no outdated. Production Planning \& Control, v. 13, n. 6, p. 497-506, 2002. http://dx.doi. org/10.1080/09537280210162941

BLACK, K. T. The design of the factory with a future. New York: McGraw-Hill, 1991.

BLACKBURN, J. The time factor. In: BLACKBURN, J. Time-based Competition - The next Battleground in Manufacturing. Homewood: Business One Irwin, 1991.

BURBIDGE, J. L. Production Flow Analysis. Oxford: Clarendon Press, 1989.

BURBIDGE, J. L. Period Batch Control. Oxford: Clarendon Press, 1996.

CACHON, G. P.; SWINNEY, R. Purchasing, pricing, and quick response in the presence of strategic consumers. Management Science, v. 55, n. 3, p. 497-511, 2009. http://dx.doi.org/10.1287/mnsc.1080.0948

CACHON, G. P.; SWINNEY, R. The value of fast fashion: quick response, enhanced design, and strategic consumer behavior. Management Science, v. 57, n. 4, p. 778-795, 2011. http://dx.doi.org/10.1287/mnsc. 1100.1303

COUGHLAN, P; COGHLAN, D. Action research for operations management. Internatinal Journal of Operations \& Production Management, v. 22, n. 2, p. 220-240, 2002. http://dx.doi.org/10.1108/01443570210417515

DRAKE, M. J.; MARLEY, K. A. The evolution of quick response programs. In: CHENG, T. C. E.; CHOI, T.-M. (Eds.). Innovative quick response programs in logistics \& supply chain management. Berlin: Springer, 2009.

FERNANDES, F. C. F.; GODINHO FILHO, M. Planejamento e controle da produção dos fundamentos ao essencial. São Paulo: Editora Atlas, 2010.

FERNANDES, F. C. F.; GODINHO FILHO, M.; BONNEY, M. A proposal for integrating production control and quality control. Industrial Management \& Data Systems, v. 109, p. 683-707, 2009. 
FERNANDES, F. C. F.; MACCARTHY, B. L. Production Planning and Control: the gap between theory and practice in the light of modern manufacturing concepts. In: INTERNATIONAL CONFERENCE ON CAD/CAM ROBOTICS \& FACTORIES OF THE FUTURE, 1999, Águas de Lindóia. Proceedings... Águas de Lindóia, 1999. v. 1, p. MF2-1-MF2-6.

FERNANDES, F. C. F.; MURARI, L. S. Diagnóstico dos principais problemas na indústria de calçados femininos. Tecnicouro, v. 20, n. 3, 2000.

FERNANDES, N. O.; CARMO-SILVA, S. Generic POLCA - a production and materials flow control mechanism for quick response manufacturing. International Journal of Production Economics, v. 104, p. 74-84, 2006. http:// dx.doi.org/10.1016/j.ijpe.2005.07.003

FIORITO, S. S.; MAY, E. G.; STRAUGHN, K. Quick response in retailing: components and implementation. International Journal of Retail \& Distribution Management, v. 23, n. 5, p. 12-21, 1995. http://dx.doi. org/10.1108/09590559510147127

FISHER, M.; RAMAN, A. Reducing the cost of demand incertainty through accurate response to early sales. Operations Research, v. 44, n. 1, p. 87-99, 1996. http:// dx.doi.org/10.1287/opre.44.1.87

FISHER, M.; RAJARAM, K.; RAMAN, A. Optimizing inventory replenishment of retail fashion products. Manufacturing Service Operations Management, v. 3, n. 3, p. 230-241, 2001. http://dx.doi.org/10.1287/ msom.3.3.230.9889

FORZA, C.; VINELLI, A. Quick response in textileapparel industry and the support of information Technologies. Integrated Manufacturing Systems, v. 8, n. 3, p. 125-136, 1997. http://dx.doi. org/10.1108/09576069710181947

HANDFIELD, R. B.; BECHTEL, C. The role of trust and relationship structure in improving supply chain responsiveness. Industrial Marketing Manangement, v. 31 , p. 367-382, 2002. http://dx.doi.org/10.1016/ S0019-8501(01)00169-9

HANDFIELD, R. B. Reengineering for time-based competition. Homewood: Business One Irwin, 1995.

HOEK, R. I. van. The rediscovery of postponement a literature review and directions for research. Journal of Operations Management, v. 19, p. 161-184, 2001. http://dx.doi.org/10.1016/S0272-6963(00)00057-7

HUNTER, N. A.; VALENTINO, P. Quick response - tem years later. International Journal of Clothing Science and Technology, v. 7, n. 4, p. 30-40, 1995. http://dx.doi. org/10.1108/09556229510094841

KRISHNAN, H.; KAPUSCINSKI, R.; BUTZ, D. A. Quick response and retailer effort. Management Science, v. 56, n. 6, p. 962-977, 2010. http://dx.doi.org/10.1287/ mnsc. 1100.1154

LEITE, R. B.; FERNANDES, F. C. F. Perfil dos pequenos e médios fabricantes de calçados da cidade de Birigui. Tecnicouro, outubro 2003.

LIANG, 1.; GUO, B. The evaluation for the missiontime of quick response manufacturing system. In: INTERNATIONAL JOINT CONFERENCE ON COMPUTATIONAL SCIENCES AND OPTIMIZATION, 2009, Sanya. Proceedings... Sanya, 2009. p. 390-394.
MAcCARTHY, B. L.; FERNANDES, F. C. F. A multidimensional classification of production systems for the design and selection of production planning and control systems. Production Planning \& Control, v. 11, n. 5, p. 481-496, 2000. http://dx.doi. org/10.1080/09537280050051988

MIGUEL, P. A. C. (Org.). Metodologia de Pesquisa em Engenharia de Produção e Gestão de Operações. Rio de Janeiro: Campus Elsevier, 2010.

PERRY, M.; SOHAL, A. S. Effective quick response practices in a supply chain partnership - na Australian case study. International Journal of Operations \& Production Management, v. 21, n. 5-6, p. 840-854, 2001. http://dx.doi.org/10.1108/01443570110390516

RIEZEBOS, J. Design of POLCA Material Control Systems. International Journal of Production Research, v. 48, n. 5, p. 1455-1477, 2010. http:// dx.doi.org/10.1080/00207540802570677

ROHR, S. S.; CORRÊA, H. L. Time-Based Competitiveness in Brazil: Whys and Hows. International Journal of Operations and Production Management, v. 18 , n. 3, p. 233-245, 1998. http://dx.doi. org/10.1108/01443579810196453

Silva, F. M. da; Fernandes, F. C. F. Proposta de um sistema de controle da produção para fabricantes de calçados que operam sob encomenda. Gestão \& Produção, v. 15, n. 3 , p. 523-538, 2008.

STALK, G. Time: The next source of competitive advantage. Harvard Business Review, p. 41-51, 1988.

STALK, G.; HOUT, T. Competing against time. New York: The Free Press, 1990.

STUMP, B.; BADURDEEN, F. Integrating lean and other strategies for mass customization manufacturing: a case study. Journal of Intelligent Manufacturing, v. 23, n. 1, p. 109-124, 2009. http://dx.doi.org/10.1007/ s10845-009-0289-3

SURI, R. Quick Response Manufacturing: A Companywide Approach to Reducing Lead times. Portland: Productivity Press, 1998

SURI, R. It's about time - the competitive advantage of quick response manufacturing. New York: Productivity Press (Taylor \& Francis Group), 2010.

THIOLLENT, M. Pesquisa-ação em organizações. São Paulo: Atlas, 1997.

THIOLLENT, M. Metodologia da Pesquisa-ação. 9. ed. São Paulo: Cortez, 2000.

TURRIONI, J. B.; MELLO, C. H. P. Pesquisa-ação na engenharia de produção. In: MIGUEL, P. A. C. (Org.). Metodologia de pesquisa em engenharia de produção e gestão de operações. Rio de Janeiro: Elsevier Editora, 2010.

UPTON, D. M. Flexibility as process mobility: the management of plant capabilities for quick response manufacturing. Journal of Operations Management, v. 12, p. 205-224, 1995. http://dx.doi.org/10.1016/0272-6963(95)00004-C

WANKE, P. Gestão de estoques na cadeia de suprimento: decisões e modelos quantitativos. 2. ed. São Paulo: Editora Atlas, 2008.

ZELENOVIC, D. M.; TESIC, Z. M. Period batch control and group technology. International Journal of Production Research, v. 26, n. 3, p. 539-552, 1987. http://dx.doi. org/10.1080/00207548808947883 